\title{
DEVELOPING AN AREAL VIEW OF INTONATION IN EASTERN BANTU
}

\author{
Nancy C. Kula \\ University of Essex; \\ nckula@essex.ac.uk
}

\begin{abstract}
This paper is an initial attempt at trying to synthesise the state-of-art in the study on intonation in Bantu languages. The goal is to specifically investigate what central features emerge in the comparison of four Bantu languages to allow us to formulate a hypothesis on areal features and variation in Eastern Bantu languages. The base language used for the comparison is Bemba, for which details of local intonational effects such as final lowering in utterances, as well as global effects, such as pitch range expansion in questions, are provided. These same questions are compared and contrasted with findings in the literature on Chichewa, Tumbuka and Shingazidja. The results show that there are a number of areas of symmetry and areas of contrast, which allow us to begin to define features where we can expect parametric variation in Eastern Bantu languages.
\end{abstract}

Keywords: Intonation, Tone, Eastern Bantu Languages, Focus, Questions, Pitch Range Expansion, Local and Global Effects

\section{Introduction}

Intonation in tonal Bantu languages is an area of research that is still in its infancy. Although the idea that tone languages also have intonation has long been demystified, there are very few detailed studies of the intonational structure of Bantu languages with no significant exposition of the complete intonational grammar of any Bantu language. This is in contrast to the study of tone for which Bantu languages, and African languages more broadly, are renowned, with significant impact on theoretical thinking in phonology as seen in, for example, the work of Goldsmith (1976), Leben (1973), Clements (1979), Batibo (1976, 1991), Chebanne et al., (1997). There is, however, recent emerging interest in intonation in African tone languages as showcased in the Downing and Rialland (2017) volume. The study of intonation does require the study of tone systems as one of the central questions for tone languages is how and whether tone and intonation interact. Since some headway has been made in the study of tonal systems, although this is still by 
far much less than work done on segmental phonology, there is sufficient work to guide new descriptions and which can then serve as the basis for more detailed intonational work. In addition, turning the tables around, perhaps intonational studies can be used as a starting point for the study of tone, particularly as this relates to boundary phenomenon. The central crucial difference between tone and intonation is that tone is lexically specified in a word, with tone associated to each tone bearing unit in a word or part of a word. Tone can of course occur wider than the word in phonological phrases, through spreading processes, but once processes go beyond this size and become cross-word or crossphonological phrase phenomena, we start moving into the realm of intonation. Intonation, in contrast to tone, involves larger chunks of speech amounting to utterances, which may also have internal phrases, which are normally treated as smaller intonational phrases. We normally think about the curves of an utterance in intonation and are interested in identifying the significant events that occur during the course of an utterance. These significant intonational events during an utterance are the central characteristics we look at in order to determine the intonational structure. The classic works offering introductions are Bolinger (1978) and Cruttenden (1997), with more recent work on tone and intonation in Gussenhoven (2004), Ladd (2008) and references therein.

The goal of this paper is, in this sense, to begin to draw out what the salient intonation events are in Bantu languages and more importantly how we can study them. The paper will look at some Bantu languages from the central and eastern area, and based on previous work, aim at drawing out the similarities and differences in intonational patterns and events, to come up with some initial hypotheses of what structures are prevalent and also what areas in the intonational structure are most likely to be locations of significant events. The goal is to broadly identify whether there are some Eastern Bantu features that begin to emerge from the language comparison. The findings are then used to feed into the creation of a rubric, in the form of an intonation investigation protocol, that can be used to study intonation in a broader set of Bantu languages. This would then help us develop a larger sample of languages that will allow us to begin to understand the areal features of intonation in Bantu languages more broadly.

The wider implication of this work in the digital age is that such studies of intonation allow us to technologically, via acoustic analysis, develop the skills to work with speech data that can then feed into the development of computer-based systems in the commercial world.

The paper is structured as follows. Section two discusses the data that will be used in the comparative investigation and talks about the role of tone in intonation, also presenting some background tone data. Section three looks at local effects of intonation and their sometimes varied implementation, ending with a comparison across the four languages considered. Section four contrasts with Section three by looking at global effects; and Section five recaps the emerging areal features and provides some concluding remarks. An appendix offers an intonation investigation guide for initial intonation study, based on the attested features discussed in the paper. 


\section{Data Sources and the Role of Tone in Intonation}

The data that will be used in this study is based on some published sources on intonation drawn from Downing and Rialland (2017). This choice is made so as to reflect the most recent work in this area but also, for easier comparison, work that is employing more or less similar intonational labeling conventions, broadly following the basic assumptions of an Auto-segmental Metrical Theory paradigm (Pierrehumbert, 1980, et seq., as well as subsequent recent work and modifications; e.g. Pierrehumbert \& Beckman 1988, Ladd 1996, 2008). Specifically, a comparison will be made between four Bantu languages that we can broadly classify as being Eastern Bantu. Although this is not a proposal to suggest a sub-branch of Bantu, a number of studies have shown some contrast for some features between what may be termed as Western Bantu in contrast to Eastern Bantu (see e.g. the discussion of vowel copying in Kula \& Marten, 2019). This starting point, which is also based on convenience sampling, decides to focus on languages which are geographically proximate as a basis from which to evaluate any emerging features.

The languages of focus are Bemba (Kula \& Hamann, 2017, Kula, 2011) spoken in Zambia but also the Democratic Republic of the Congo; Shingazija dialects $(2007,2017)$ spoken on the Comoro Islands (and which were originally considered to be closely related to Swahili); Chichewa (Downing, 2008, 2017, Downing, Mtenje \& Pompino-Marshcall, 2004, Myers, 1996, 1999) and Tumbuka (Downing, 2008, 2017), both spoken in Malawi and Zambia, with the data referred to here coming from Malawi. One issue that the paper does not take into account (apart from for Shingazidja where the data is available) is variation between any dialects of these languages, as well as possible contrasts across different countries where languages are spoken across borders. Details of the dialects/ sources of data will be discussed at each relevant point, and it is hoped that the language varieties showcased here may form the basis of future comparative work of other dialects. One caveat with the data though, is that the data used were sourced from the literature where their intention was for purposes other than making a wider comparison and so naturally, there are gaps where like for like comparisons of particular structures between languages cannot be made, and also where data with a different intention are used to glean some structures for which more tokens would have been beneficial. It is, therefore, a starting point for a more detailed, directed comparative work but this study treat it as a very positive outcome that we are in a position to even begin to make such comparisons for the structure of intonation in Bantu languages.

In general, and as would be expected, data used for the study of intonation involves longer stretches of sentences and utterances. This raises the question, as for other linguistic work, of whether naturally occurring data are to be preferred for such studies, over more laboratory created, elicitation type of data spoken out of context. This continues to be a topic of discussion in linguistic work and the consensus seems to be that we need a bit of both. While naturalistic data are preferable, there are a number of cases where in order to verify a particular structure, more tokens of the same structure are needed. These, however, may not occur naturally in a data collection recording setting. More tokens are crucial for drawing robust generalisations, and show how much a particular contrast is maintained 
in multiple tokens for the same speaker and also for multiple speakers. Furthermore, in some work, multiple tokens are crucial for drawing statistical conclusions. In addition, and in particular for the study of intonation that involves acoustic analysis, it is important to use segments (like sonorants) that have more resonance and, therefore, able to produce a continuous pitch track without breaks brought on by sounds with more constriction such as obstruents. In this case, it becomes necessary to construct sentences which may be a little awkward but which provide optimal conditions for more accurate analysis. In each case though, all sentences would be judged as linguistically grammatical even if sometimes the contexts in which they may be used are constructed and require a stretch of imagination. Of course, the best position would be to be creative in balancing both requirements of naturalness and linguistic requirements in data elicitation.

With these background data remarks, let us consider in more detail the nature of intonation data in tone languages like we see across Bantu. Tone in Bantu languages as is well known, plays a crucial role both at the lexical and grammatical level. Most Bantu languages have a $\mathrm{H}$ vs. $\mathrm{L}$ distinction where it is phonologically assumed that the systems consist of $\mathrm{H}$ vs. $\varnothing$ since it is mainly $\mathrm{H}$ tones that are active and $\mathrm{L}$ tones are considered the default, or as inserted post-lexically, ensuring that each tone bearing unit (TBU) has a tone on the surface. Tones are well established as undergoing a number of spreading processes within the word and beyond. Recent work in articular has revealed a number of tonal processes beyond the word were bigger constituents such as phonological phrases are formed. This means that tone is used to indicate domains bigger than the word. This may lead us to question why those same tones are not the markers of intonation? That is, why is the intonation of a tone language not just the sum total of the tones involved in a particular utterance? Is there an independent and different representation of intonation that is distinct from the tones? Particularly, when tone can mark constituents larger than the word.

Following work from the mid 80's in Nespor and Vogel (1986) and Selkirk (1986 et. seq.), we assume there is some kind of prosodic hierarchy in utterance structure as given in 1 below. The main focus in this paper will be on the constituents below the word level. ${ }^{1}$

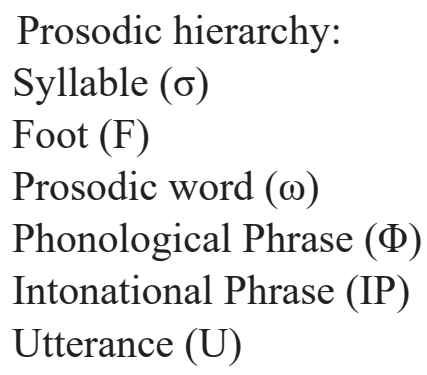

This hierarchy implies that syllables make up prosodic words, which then can be combined in different ways to create phonological phrases. Phonological phrases can then combine to create intonational phrases and finally, these can be phrased into utterances which express a complete thought. Since 'tone' will also be relevant at the intonational level, it is important for the ensuing discussion to distinguish the different types of tone. Lexical tone will as standard be used to refer to tone that is part of the lexical

${ }^{1}$ Nespor and Vogel (1986) also have a Clitic Group bellow X that is not represented here. 
representation of a word. It is this tone that undergoes spreading within the word and at the phonological phrase level. At the intonational phrase level, we will refer to intonational tones which mark significant tonal events at the intonational level. We return to these tone in later discussion. The contrast between the two types of tone is that while lexical tone is present on each vowel of each word, intonational tones are limited to occurring at specific junctures that are important for defining the intonational profile of a given sentence. Intonational tones are used to mark tone across all languages and are not limited to languages with lexical tone. The classic intonation examples in Western languages is English where questions are said to have a rising intonation. ${ }^{2}$ These are considered to be marked with a right edge intonational tone denoted with $\mathrm{H} \%$. This intonational $\mathrm{H} \%$ on the right edge of an utterance in English would then act as a target at which the speakers' intonation is aimed at producing a question. Other relevant intonational tones will be introduced at the relevant junctures. Importantly, intonational tones do not show the kinds of spreading patterns that lexical tones do since their role is quite different - they mark significant junctures in the overall intonation of an utterance. There can, however, be some interaction between lexical tone and intonational tone (see, for example, discussion in Hyman and Monaka, 2008) and the implementation of intonational tone, meaning how it is aligned with an utterance, may vary. We will see some examples of this. Interaction between the two kinds of tone is an important ingredient in understanding the intonation of tone languages and is an area in which more detailed work is needed.

Having a good grasp of the tone of a language is important to understand and correctly analyse intonation. It is important for demonstrating the fact that these two systems apply at different levels and significantly, that it is too simplistic to assume that the intonational structure of a tone language will be the sum of its lexical tones. The base language we will work with in this comparative study is Bemba, on which the authors has previously conducted research and which is a good starting point for comparison. The next section presents the summary of the central lexical tone processes in Bemba and in particular those that apply at the phonological phrase level based on previous work. This information is important in understanding the data presented in the acoustic representations to be discussed in the rest of the paper. However, the lexical tone processes themselves, are not crucial for the analysis and understanding of the intonational structures which are the central focus of this paper.

\section{Bemba Tonology}

Tone in Bemba has good basic descriptions starting with the early work of Sharman and Meeussen (1955); Sharman (1956) that focuses on the tense system; and Guthrie (1945) who presents the tone of nominals in his PhD thesis. This work focuses on Northern Bemba which is considered the central dialect with language consultants said to be from Kasama. Kashoki (1968); Givón (1972); Mann (1977), and Philippson (1998), then follow from the late 60 s to the 90 s. In more contemporary times we have Bemba tone work from

2 This is particularly so for yes/no questions like 'Did Mutale go to the market?'. There may be variation with respect to how much rise there is in different kinds of questions. 
Bickmore and Kula, (2013); Kula and Bickmore, (2015) and Hamann and Kula, (2015). ${ }^{3}$ In the latter works, we focus also on what we loosely term 'Copperbelt Bemba' and also make comparisons with Northern Bemba and what is reported in the literature. ${ }^{4}$ Here, this article will highlight two central $\mathrm{H}$ tone spreading processes and their interaction with downstep (see Clements \& Ford, 1979 for a classic explanation of downstep). An important aspect of Bemba and indeed most Bantu tone is tone associated to TAM (tenseaspect-mood) markers. These tones, referred to as Melodic Tones (Odden \& Bikcmore, 2014), also play a crucial role in the tonology of Bantu languages. These are discussed in detail in Bickmore and Kula (2013) and will not be elaborated on here. Therefore, TAMs that do not have Melodic Tones are used in the presentation below for ease of exposition.

\section{Tone at the Prosodic Word Level}

Within the word a $\mathrm{H}$ tone that is followed by no other $\mathrm{H}$ tones will spread to end of the domain as we see in example 2 below. The only lexical tone that we have in the underlying representation of the verb form in 2 is the initial one, on the subject marker $b \underline{a}-$-. All lexical $\mathrm{H}$ tones will be underlined. In $2 \mathrm{a}$, this initial lexical high tone spreads to the end of the domain. We call this unbounded $\mathrm{H}$ spreading. Contrast this with $2 \mathrm{~b}$ where we have a lowtoned subject marker tì-. In this case, we see that the rest of the verb is also all low. This is the motivation for assuming that the stem of the verb uku-londolola 'to explain or to introduce' is lexically low-toned. ${ }^{5}$

a. bá-ká-lóóndólól-á

2SM-FUT3-explain-FV

'They will explain'

b. tù-kà-lòòndòlòl-à

2PLSM-FUT3-explain-FV

'We will explain'

Unbounded spreading contrasts with bounded spreading where a $\mathrm{H}$ tone does not spread to the end of the domain. There are a few contexts where this happens. In example 3 it is because there is another lexical $\mathrm{H}$ tone at the end of the verb, the subjunctive marker -é. In this case, rightward spreading from the subject marker only spreads twice from the start

3 There is an impressive and growing body of work on Bemba looking at various other parts of grammar apart from tone, see for example, a very non-exhaustive list of some contemporary work in Kula (2002), Kasonde (2009), Mwansa (2011), Mweshi (2015), Mwita (2016), among others.

4 The term Copperbelt Bemba is not to be equated to 'Town Bemba' (Kashoki 1972, Kabinga 2010, Kateule 2016) and is meant to capture Bemba speakers who have migrated from the North and settled in the CB and not speakers of a sometimes transitory 'urban variety'. Although, of course these are not mutually exclusive. This is probably a project in its own right and we will for now accept the ambiguity this term/ use raises, pending further research and elaboration on the status of different varieties.

5 The representation in the examples will follow actual pronunciation which is important particularly for tone. Thus, all long vowels will be represented in the examples, even though these are not marked in orthography. In this example, vowels are always long before an NC/pre-nasalised stop in Bemba, like in most Bantu languages. In addition, most examples may appear incomplete if only the verb is the focus. The examples in (2-3), for example, would be followed by something like ifya citiike 'what happened' in actual use. 
creating a ternary domain. ${ }^{6}$

(3)

bá-ká-lóòndòlòl-ế

2SM-FUT3-explain-SUBJ

'They should explain (in the future)'

The other common process at the word-level cross-linguistically is downstep. This is where in a sequence of two (or more) high tones, one (or more) is produced at a lower register. In a number of languages, downstep is triggered by a floating low tone (Clements \& Ford, 1979, Cornell, 2001). In Bemba, downstep is the result/reflex of an OCP (Obligatory Contour Principle (Odden, 1986)) effect where two adjacent lexical H tones are disallowed and downstep applies. ${ }^{7}$ We see this in 4 where there are two lexical $\mathrm{H}$ tones underlined. The first of the subject marker spreads to the second syllable. This then creates adjacency with the following lexical $\mathrm{H}$ on the object marker, and that $\mathrm{H}$ undergoes downstep indicated by superscript /!/.

$$
\begin{aligned}
& \text { bá-ká-'tú-lúk-á } \\
& \text { 2SM-FUT3-1PLOM-plait-FV } \\
& \text { 'They will plait us (our hair)' }
\end{aligned}
$$

Thus, at the word level, at least, two processes are pervasive in the verb in Bemba bounded and unbounded spreading, with bounded spreading subject to downstep. We consider whether these same processes also apply at the phrasal level.

\section{Tone at the Phrasal Level}

We already saw the process of bounded spreading in example 3 above and this also applies at the phrasal level as in example 5 below. In this case, the lexical $\mathrm{H}$ on the subject marker spreads twice rightwards because there is another word following. We will make this description more precise presently.

bá-ká-lóòndòlòl-à bwì̀nò

2SM-FUT3-explain-FV well

'They will explain well'

The other crucial $\mathrm{H}$ tone spreading process at the phrasal level is $\mathrm{H}$-tone doubling where a tone on the final syllable of a word can spread onto the first syllable of a following word. We see this in 6 where the $\mathrm{H}$ tone on the final vowel in the verb belenga 'read' spreads onto the first syllable of the following word, a name in this case. This $\mathrm{H}$ tone does not spread any further, even though there are following TBUs available. Importantly, it also does not creates a ternary domain, otherwise, it would spread onto the first /e/ in Kapeembwa and creates a fall on the syllable as is attested in other environments in the language. In this

6 Ternary domains are of great interest in phonology. See discussion and other references in Bickmore and Kula (2013). Significantly, this is a point on which we see a difference with patterns reported in the literature for Northern Bemba, where on data from the 50's Sharman and Meeussen (1955) report binary spreading.

7 Again by contrast, Sharman and Meeussen (1955), and Sharmann1(956) do not discuss any downstep in Northern Bemba. 
case, we cannot say that it does not spread further because there is a final $\mathrm{H}$ tone at the end of the second word, since as seen above, we would expect it to create a ternary domain.
bélééng-èl-á Kápèèmbwá
read-APPL-FV Kapembwa
'Read for Kapembwa (imperative)'

Returning to the two processes of bounded and unbounded $\mathrm{H}$ spreading, it, in fact, turns out that these processes are an important diagnostic for phonological phrasing in Bemba (Kula \& Bickmore, 2015; Kula, 2016). Bounded spreading as in 6 at the phrasal level, indicates that a following word (here the proper name Kapembwa) is within the same phonological phrase as the verb. Unbounded spreading, on the other hand, where a $\mathrm{H}$ tone spreads to the end of the word, indicates the presence of an immediately following phonological phrase boundary at the phrasal level. Some examples are given in 7 below. Brackets mark phonological phrase (PP) edges. ${ }^{8}$ 2SM-FUT3-1OM-introduce-FV
'They will introduce him,
a. (bá-ká-mú-lóóndólól-á) ${ }_{\mathrm{PP}}$
b. (bá-ká-lóòndòlòl-à
2SM-FUT3-introduce-FV
'They will introduce Bupe'

In $7 \mathrm{a}$ there is an object marker - $m u$ - added onto the verb that refers to the argument Bupe. In this case, the initial lexical $\mathrm{H}$ tone spreads to the end of the verb form. This indicates a right edge PP boundary, which implies that Bupe is in another PP and is, in this sentence, an after thought. Contrast this with $7 \mathrm{~b}$ where there is no object marker and Bupe is part of the same PP as the verb and the tone, therefore, shows bounded ternary spreading. This tonal spreading pattern, therefore, matches syntactic constituency where when a referential object marker is present on the verb, the referent (here Bupe) is deemed to be outside the VP. These kinds of examples are interesting for the phonology-syntax interface where we can see that phonology, through the tonal pattern, and cues syntactic constituency. These patterns also correlate to the so called conjoint-disjoint distinction in Bemba (Kula, 2016).

In the investigation of phonological phrasing in Bemba, in Kula and Bickmore (2015, we show that these same tonal spreading patterns result in the following PP patterns in the language, showing the predicted interaction between phonology and syntax.

(8) Bemba Phonological Phrasing
(Verb - Adverb)
(Noun - Adjective)
(Noun - Possessive)
(Subject) (Verb)

\footnotetext{
8 In the interest of comparability of examples in 6, with those in 2-4 the same verb ukulondola, which can also mean 'to introduce' is used, although this creates a less natural example.
} 
(Verb Object) (Adverb)

(Verb Object) (Object)

(NP) $($ Conjunction=NP)

(NP Object) (Verb)

(Verb with OM) (Object)

(Verb) (NP Subject)

(Verb with OM) (Object) (Object) (Adverb)

This patterning at the phrasal level based on tonal spreading patterns of lexical tone shows that lexical tone, apart from its role at the lexical and grammatical level, also plays a crucial role at higher levels, namely; the phonological phrase. This is a good place to start investigating intonation to see how much it differs from this. It will be shown that intonation applies at a higher prosodic level indicating larger domains although there are also smaller domains that are indicated.

\section{Local Effects of Intonation}

As discussed earlier, intonation involves intonational tones that are used to mark the overall structure of a sentence or an utterance. We will distinguish two uses of intonational tones that will shape the discussion. We will look at local effects, where the intonational tone applies to a small portion of a sentence, in contrast to global effects where either a whole or a larger part of a sentence/utterance is affected. In Bemba, local effects are marked on the right edge, while global effects are generally, usually marked on the left edge.

In terms of representation, intonational tones can be distinguished from lexical tone as the $\mathrm{H}$ and $\mathrm{L}$ are associated with an additional diacritic that determines the location of the tone. $\%$ is used to indicate a boundary tone so that $\mathrm{L} \%$ and $\mathrm{H} \%$ are boundary tones on the right edge. A symbol on the left of the tone indicates a left edge intonational tone for example, $-\mathrm{H}$ or $-\mathrm{L}$.

\section{Boundary $\mathrm{L} \%$ and $\mathrm{H} \%$}

A central boundary tone is found at the end of different sentences that will be considered in Bemba in final lowering. Final lowering is a lowering effect confined to constituent ends, and affects (that is can occur in the context of) both $\mathrm{L}$ and $\mathrm{H}$ lexical tones (Connell \& Ladd, 1990). An interesting feature of final lowering is that it can be associated just to the final TBU of a sentence or to a range of TBUs. In Bemba, final lowering occurs after subjects, topics, and clause, finally. There is variation in the implementation of the boundary L\% with subjects and topics having punctual implementation that is associated with the last TBU. In contrast, at the end of the clause, the boundary L\% aligns anywhere from the last three to five syllables. Myers (1996) is one of the early works to note this for Chichewa. These contrasting implementations are illustrated in Figure 1 below illustrating example 9. ${ }^{9}$ Figures are replicated from Kula and Hamann (2017) where further exemplification can also be found.

bànàmáàyó

$$
\text { bá-ká-bílà }
$$

2SM-FUT3-sew-FV

ìfyákùfwáálá

8clothes

The verb in 9 is homophonus with the verb $u k u$-kabila 'to crave/desire' but in $9 k a$ - is the future marker. The tone would also be different for the verb stem -kabila, which with an initial lexical high would have a downstep: bá-'kábílà 'they crave'. Thanks to Lombe Musonda (pc.) on the discussion of this point. 
'The women will sew clothes'

The following figure and figures henceforth, have five tiers representing from the top down after the pitch track, the syllable tier, breaking the sentence into syllables although note that gliding and vowel lengthening/fusion is maintained); the lexical tone tier that only marks lexical $\mathrm{Hs}$ and not $\mathrm{Hs}$ resulting from $\mathrm{H}$ spreading (the spreading rules discussed above apply); the intonational tone tier where intonational tone is marked; the intonational effect tier where the main intonational effect is indicated; and finally, the tier that holds the gloss of the sentence. Figures were produced using Praat (Boersma and Weenink 2014), which is freely downloadable.

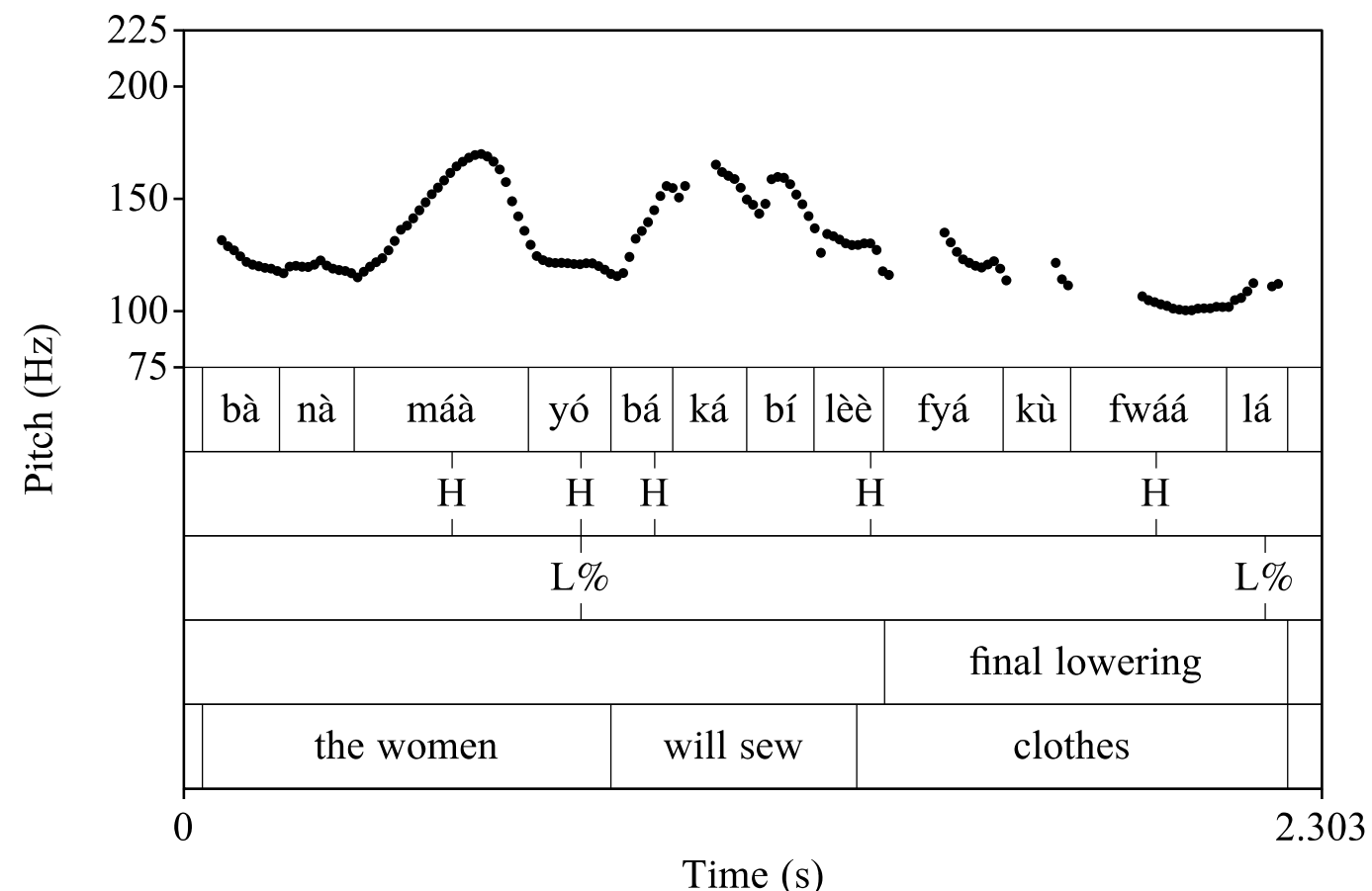

\section{Figure 1: Subject Final L\% and Sentence Final L\%}

In Figure 1, we see lowering at the end of the subject, and notice here that the boundary tone $\mathrm{L} \%$ is mismatched with the lexical tone which is $\mathrm{H}$. Secondly, the boundary $\mathrm{L} \%$ only aligns with the final TBU of the subject bànàmáàyó. This contrasts with the sentence's final L\% that aligns with the last two syllables/last three TBUs at least. In this case as well, the intonational $\mathrm{L} \%$ is mismatched with the lexical tone which is $\mathrm{H}$. This is the evidence that shows that tone and intonation are independent: For lexical tone, it occurs on every TBU and for intonation, there are two significant events in the profile of this declarative sentence.

One question, however, is what happens when lexical tones and intonational tones coincide as in the above. Does the intonational tone replace the lexical tone? In this instance, we 
assume that rather than replace the lexical $\mathrm{H}$ at the end of the subject in Bemba, the boundary L\% likely only lowers the final lexical $\mathrm{H}$. One argument for this is that the process of High doubling that we saw above, where a $\mathrm{H}$ at the end of a word can spread onto the first syllable of a following word (see example 6) still applies in such contexts. 9 does not show this as the following verb has an initial $\mathrm{H}$, but if a low toned subject marker like $t u$ - $\left(1^{\text {st }}\right.$ pl.) was used, then inter-word high doubling would apply.

We may also wonder whether the subject final L\% seen in Figure 1 is because of the size of the subject, which is just one word and, therefore, there is no space for the L\% to be associated with more syllables on the right edge. This turns out not to be the case as when larger sentential subjects like a fronted complementiser clause are used, we still get punctual implementation of the boundary $\mathrm{L} \%$ at the end of the large subject. This is illustrated in Figure 2 below for example, 10.

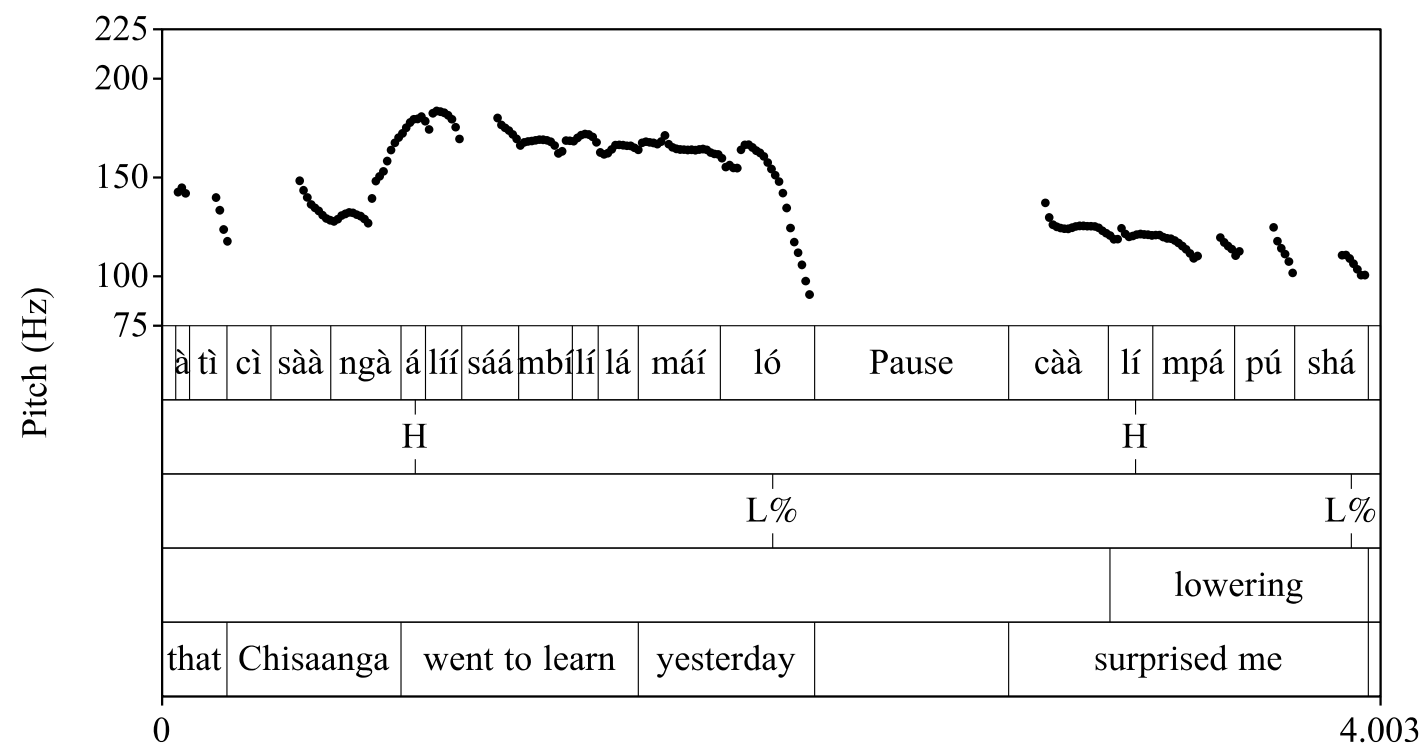

Time (s)

Figure 2: Fronted Complementiser Clause with Boundary L\% and Main Clause with Lowering/Compression

(10) àt

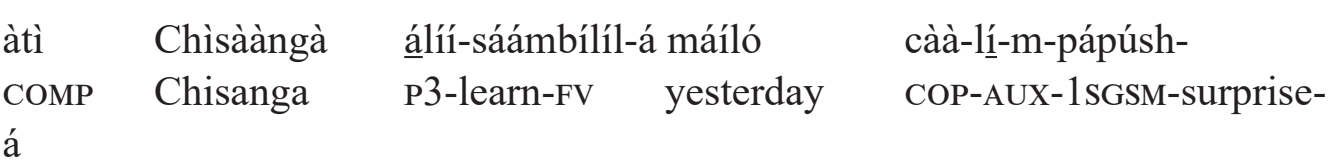

FV

'That Chisanga went to learn/study yesterday surprised me'

In Figure 2, despite the much longer fronted sentential complementiser, which also has $\mathrm{H}$ tone from the verb onwards, the boundary $\mathrm{L} \%$ still only attaches to the final syllable so that the pitch track shows a continued held high shape with a fall only at the end. We see pitch reset, where the pitch tracks goes from the fall to start again at the normal pitch range of the speaker, around $150 \mathrm{~Hz}$, with the rest of the main clause gradually going down 
lowering. We can also consider the matrix clause to be mainly compressed in this instance. We see a similar boundary L\% effect in contrastive topic constructions as in the example $11 . .^{10}$

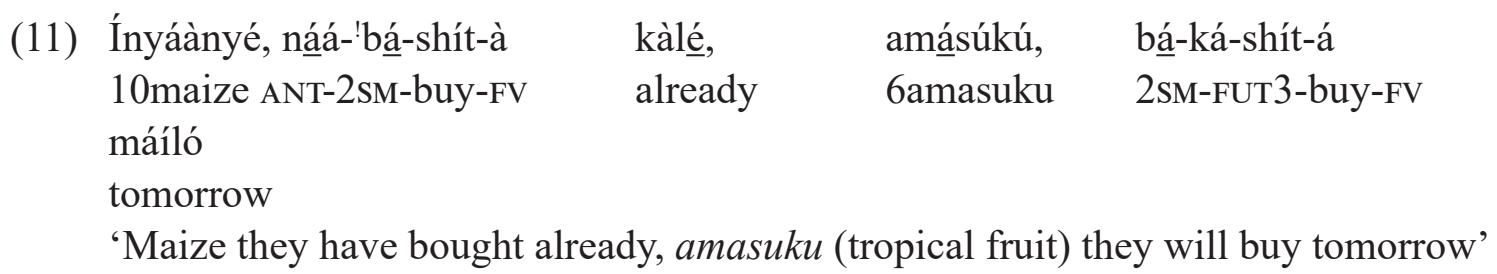

In 11 , the subjects are the two constituents contrasted and both of them end with a boundary $\mathrm{L} \%$ in intonation although they have a $\mathrm{H}$ lexical tone. In addition, the whole initial sentence shows final lowering at 'already' and then also at the very end on 'tomorrow,' with the preceding L\% of the first clause being more punctual than that on mailo where lowering starts at the final syllable of 'buy'.

We can, thus, summarise the occurrence of boundary L\% in Bemba as used to mark the following sentence types given in 12 .

(12) Boundary L\% in Bemba is used to mark:

(i) The end of a declarative

(ii) Subjects

(iii) Sentential topics

(iv) Complementiser clauses

(v) Contrastive topics

The contrast to a boundary $\mathrm{L} \%$ is a boundary $\mathrm{H} \%$. This is also found in a few constructions in Bemba (of those investigated thus, far). Specifically, restrictive relative causes and some contrastive topics show a right edge boundary $\mathrm{H} \% .{ }^{11}$ We have already seen contrastive topics being marked with a boundary $\mathrm{L} \%$, and this seems to be in the majority of cases but there were also a few cases where a boundary $\mathrm{H} \%$ was used. More data is needed to make more substantive claims about this and it will, therefore, not be discussed further here. In restrictive relative clauses, (where the head noun and the relative clause are in the same domain) on the other hand, right edge $\mathrm{H} \%$ is robustly attested. Consider the relative clause in 13 below and its corresponding Figure 3.

\begin{tabular}{|c|c|c|c|}
\hline ́́shì & à-bá-bíl-à & bwì̀nò bá-léé-'ángálà & kùmùmànà \\
\hline 2girl & 2AUG.REL-2SM-sew-FV & well 2sM-PROG-play-FV & 16rive \\
\hline
\end{tabular}

10 Topic relates to aboutness, what a particular utterance is about. This contrasts with focus understood broadly as new information in an utterance vs. backgrounded/given information. There can be different kinds of focus (new, contrastive, alternative, etc.). More formal and precise definitions can be found in a number of works, (see e.g. Zubizarreta, 1998; Lambrecht, 1994; Frascarelli, 2000; Buering, 2012, among others).

11 See Kula (2007), Kula and Cheng (2007) for more detailed discussion of phonological phrasing in Bemba relative clauses. Givón (1972) also offers good discussion. 


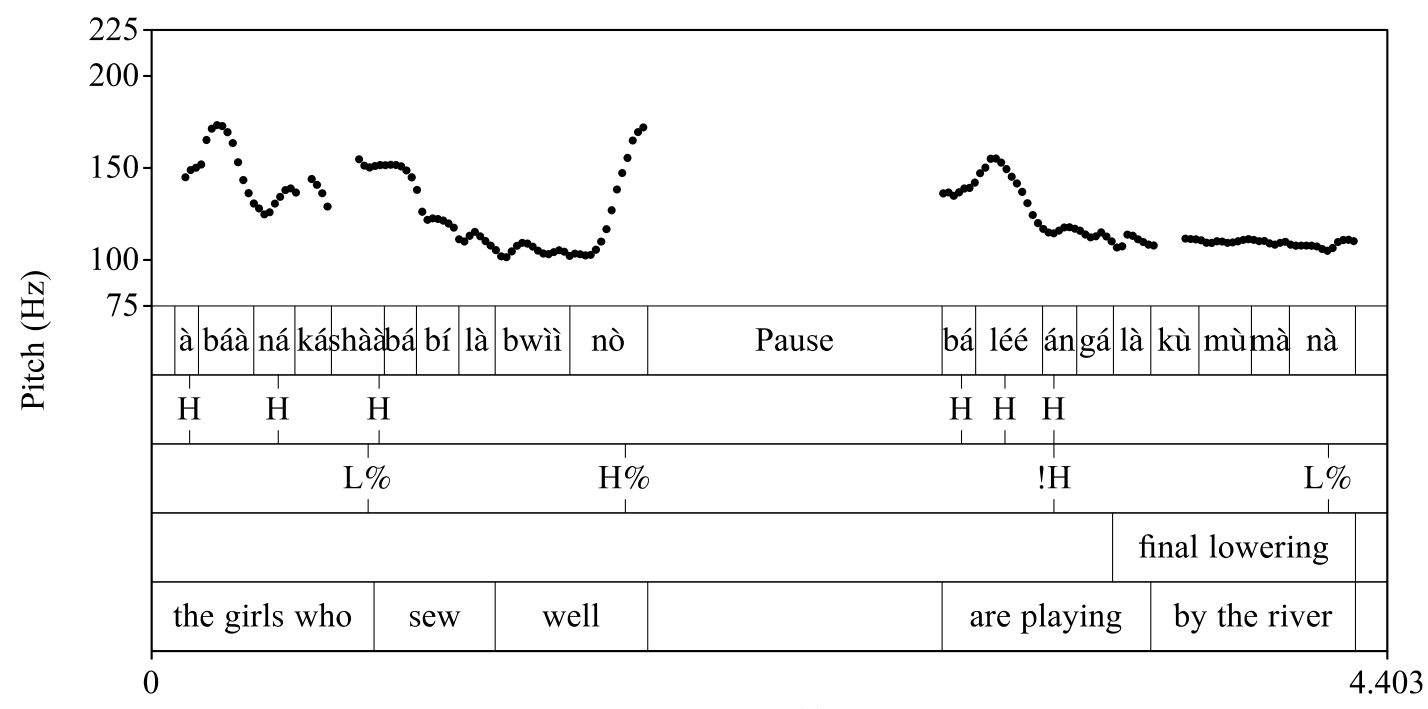

Time (s)

\section{Figure 3: Relative Clause with Continuation Rise and Main Clause with Lowering (Bemba)}

Notice that in the relative clause in 13 , the final word bwiino, has lexical low tones, but the intonation is marked with a boundary $\mathrm{H} \%$ at this edge, again showing the independence of lexical tone and intonation. In terms of implementation, unlike final lowering at the end of a declarative, the $\mathrm{H} \%$ is associated only with the final syllable in Figure 3. Furthermore, we get pitch reset at the start of the following matrix clause, which also shows another important intonational tone - a sentential downstep marked as H!. Here, we see downstep applying to all following highs when there are two lexical Hs adjacent (as discussed in section 2 above), which then immediately goes into final lowering.

\section{Role of Discourse Functions in Boundary Tone Implementation}

In the implementation of boundary tones for local effects, we see two contrasting patterns; on the one hand, a boundary tone is punctually associated with a final syllable, as seen at the end of subjects of any size, contrastive topics and also restrictive relative clauses and on the other hand, every instance of a boundary tone that occurs in the very ultimate position of an utterance, whether it is a simplex matrix clause or a complex one (including a complementiser or a relative) is implemented over at least, the last three syllables.

This article develops a hypothesis here and argues that the varied implementation of the boundary tones marking intermediate intonational phrases is connected with discourse functions that is the role that an intermediate phrase plays in an utterance correlates to how a boundary tone is implemented. The discourse function is termed saliency and a proposal given is that discourse salient constituents are marked punctually while nonsalient constituents, signaling termination, are marked with a longer/stretched boundary 
$\mathrm{L} \%$. This would explain the contrasts we have seen thus far. For subjects, these are usually salient in being the topic and central to what the matrix clause expresses or is about. This is why both short and much longer subjects get marked with a punctual L\%. Similarly, the relative clause is the salient part of the utterance in which it is contained, and in this instance is marked with a boundary $\mathrm{H} \%$ to indicate continuation, with the following matrix clause almost compressed. This implies that the same phonological even can be phonetically attenuated and provide discourse relevant cues. The stretched L\% implementation cues terminality that is conversationally important for turn-taking in speech, while punctual $\mathrm{L} \%$ and $\mathrm{H} \%$ indicate saliency and continuation.

\section{Eastern Bantu Comparative Data on Local Effects}

Let us now turn to consider the local effects we have seen in Bemba in a broader context. How many of the patterns presented thus far also apply to Eastern Bantu languages and does this help us begin to formulate expected patterns and observe typological features? As pointed out earlier, we will compare Bemba to Chichewa and Tumbuka (Downing 2017, Downing \& Pampino-Marshall, 2013) and Shingazidja (dialects) (Patin, 2017, 2007). To begin the discussion and in the interest of space and brevity, consider the comparative summary of the key features of comparison for local effects given in Table 1 below.

\begin{tabular}{|c|c|c|c|c|}
\hline $\begin{array}{c}\text { Intonational } \\
\text { Constituent }\end{array}$ & Bemba & Shingazidja & Chichewa & Tumbuka \\
\hline Declarative end & $\mathrm{L} \%$ & $\mathrm{~L} \%$ & L\% (declination) & $\mathrm{L} \%$ \\
\hline Subject & $\mathrm{L} \%$ & $\mathrm{H} \%$ & $\mathrm{H} \%$ & $\mathrm{H} \%$ \\
\hline Topic & $\mathrm{L} \%$ & $\mathrm{H} \%$ & $\mathrm{H} \%$ & $\mathrm{H} \%$ (super High) \\
\hline Other clauses & $\mathrm{L} \%$ & $\mathrm{H} \%$ - non final & $\mathrm{H} \%$ & $\mathrm{H} \%$ \\
\hline Contrastive topic & $\mathrm{H} \%$ & $\mathrm{LH}^{*}$ on penult & $\mathrm{H} \%$ & $\mathrm{H} \%$ \\
\hline Relative clause & $\mathrm{H} \%$ & $\mathrm{H} \%$ (for NRs) & $\mathrm{H} \%$ & $\mathrm{H} \%$ \\
\hline Penult lengthening & No & No & Yes & Yes \\
\hline PPhs and IPs & Yes & Yes & No - only IPs & Yes \\
\hline
\end{tabular}

\section{Table 1: Comparison of Local Effects between 4 Eastern Bantu Languages}

The central consistent feature across all four languages is the presence of final lowering in each case. In all languages, apart from Bemba, implementation of the final boundary L\% is punctual. So the other languages do not show the stretched final L\% we saw in Bemba. Marking ofinternal intermediate phrases where they exist is also punctual. Thus, the saliency hypothesis sketched above does not extend to the other languages in this comparative study. 
In all cases where Bemba shows an internal boundary L\% for subjects, topics and other clauses like complementiser clauses, the other languages show a boundary $\mathrm{H} \%{ }^{12}$ There is commonality between all four languages with respect to marking contrastive topics and relative clauses. All languages mark these with a boundary $\mathrm{H} \%$, apart from Shingazidja which differs in the marking of contrastive topics, where a complex intonational tone $\mathrm{LH}^{*}$ is used, involving a fall $\mathrm{H}$. In addition, in Shingazidja, the $\mathrm{H} \%$ marking in relative clauses is used in non-restrictive relative clauses (NRs), that is RCs that involve apposition or parenthetical structures, where the relative clause offers incidental information on the head noun.

An overview of all 4 languages shows that Shingazidja, Chichewa and Tumbuka pattern together on the marking of internal domain within an intonational phrase with a boundary $\mathrm{H} \%$ where Bemba would use a $\mathrm{L} \%$. Otherwise, the four languages pattern similarly for the end of a declarative, contrastive topics and relative clauses, one characteristic on which the languages are split, and which may begin to explain some of the broad contrasts seen is the absence of penultimate lengthening in Bemba and Shingazidja. Penultimate lengthening is a key marker of phrasing in a number of Bantu languages, including many Nguni languages like Zulu and Sotho. Unlike Shingazidja, which treats the penultimate position as accentual, there are no penultimate effects in Bemba. Perhaps the presence of penultimate effects in a language has particular implications for intonation that feeds into the other differences we see between Bemba and the other three languages. This is an issue we leave to future research.

Let us now consider some examples of some of the intonational patterns seen in Shingazidja, Chichewa and Tumbuka that complement or contrast with what we have already seen in Bemba. Only a representative sample will be given here. Readers are directed to the cited references for a fuller discussion. Figures 4 and 5 below are examples of intonational patterns in Shingazidja for declarative sentences and for non-final clauses in a complex sentence.

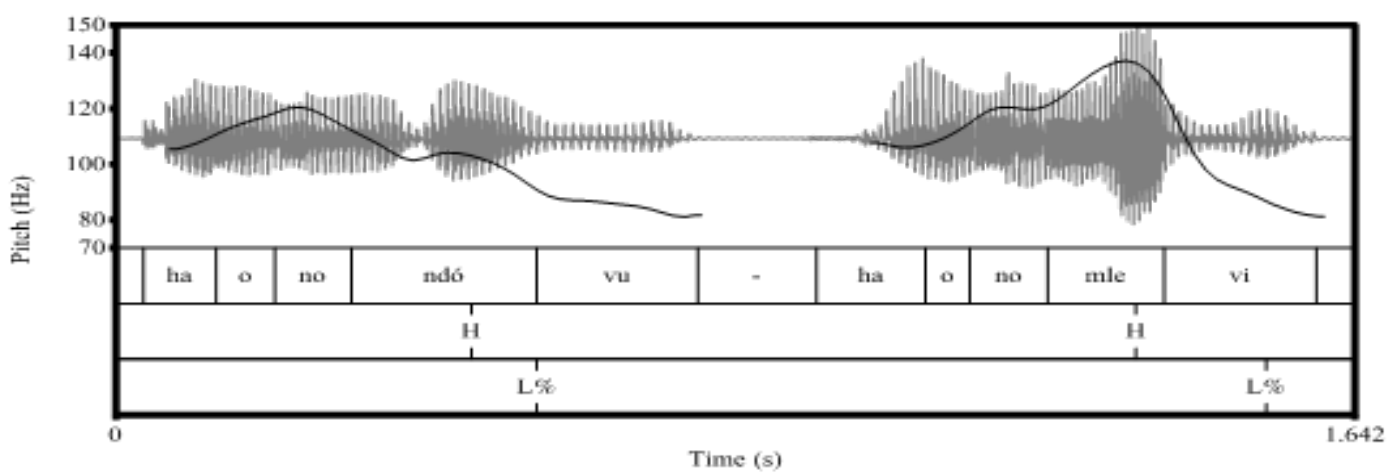

'He saw an elephant'

'He saw a drunkard'

\section{Figure 4: Final Lowering with $L \%$ at the End of Declaratives}

Figure 4 shows final lowering in the Moroni dialect of Shingazidja (Patin, 2017) where it

12 Interestingly, at the phonological phrase level, Chichewa has been shown as having no boundary following the subject, with the subject always phrasing together with the VP. Things look different at the intonation level where we see a boundary $\mathrm{H} \%$. Recall that the Chichewa data reported here is Malawian Chichewa and, furthermore, Downing's data are based on Ncheu dialect, which differs from the dialect reported in Kanerva (1990). It remains to be investigated how Zambian Chichewa/Nyanja would pattern. Although we assume it is the same cross-border language, we can also be reasonably sure that there are also dialectal differences. 
is aligned with the final syllable in both sentences, showing no stretched $\mathrm{L} \%$ as we saw in Bemba.

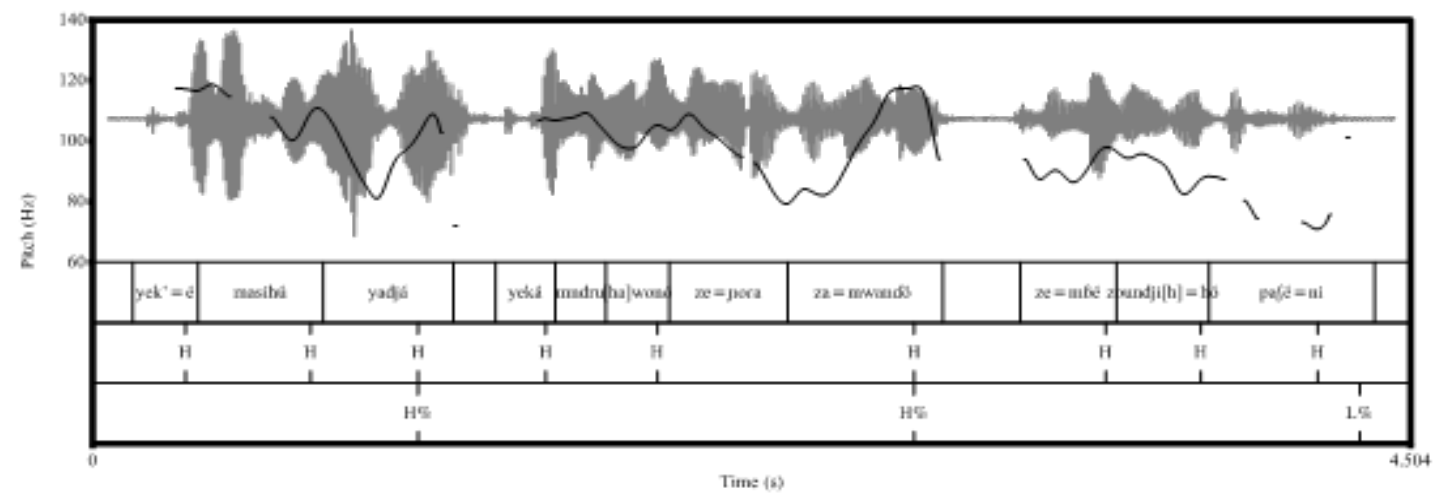

'When the night comes, when one sees the first stars, the cows come back to the kraal.'

\section{Figure 5: $\mathrm{H} \%$ at the End of Non-final Clauses}

In Figure 5, we see that in the Washili dialect, the first two non-final clauses end with a boundary $\mathrm{H} \%$ (a continuation rise) but the final one closing off the utterance shows final lowering as would be expected.

Figure 6 below shows Chichewa, where we can see that the subject (mwááná 'child') ends with a boundary $\mathrm{H} \%$ after which the pitch resets to the speaker's regular pitch range at the verb. There is final lowering which shows some gradual declination that is a gradual fall over a long stretch to the end (see Cornell, 2001 on distinguishing declination from downdrift and downstep). Interestingly also in this case, as we saw in Bemba, the final two words of the utterance have only high tones but final lowering still applies. Notice also that Chichewa has penultimate lengthening at the intermediate phrase boundary following the subject and also at the end of the utterance. There are, thus, both segmental and intonational cues for boundaries.

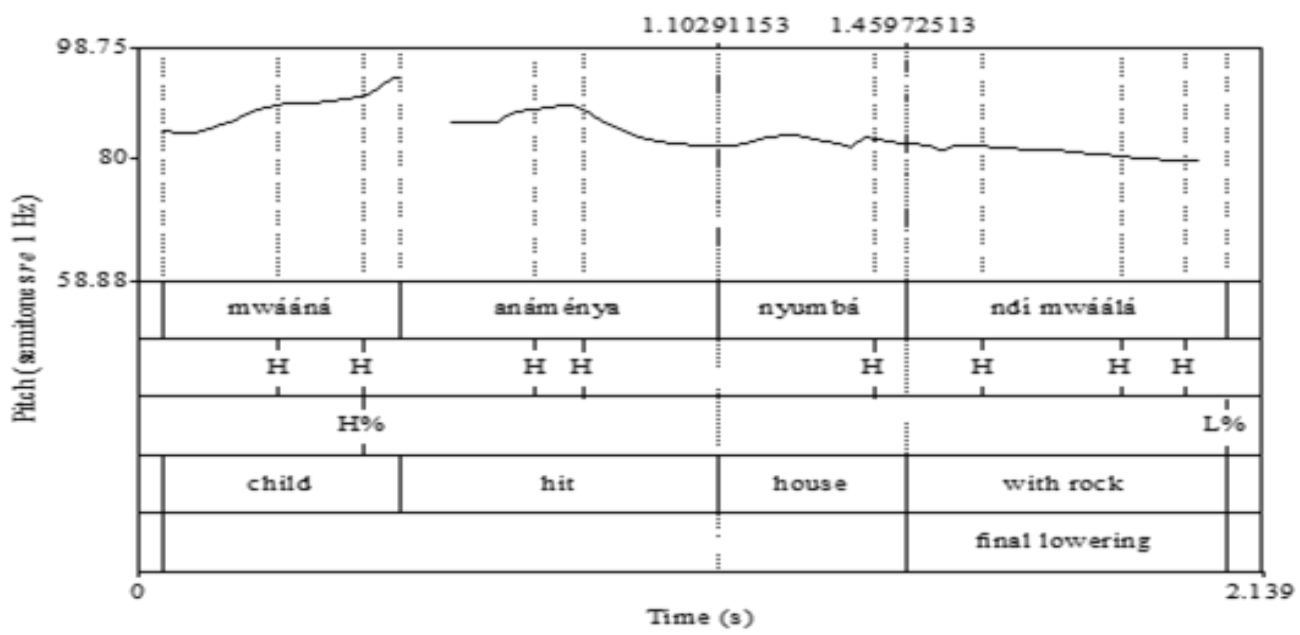

Figure 6: Chichewa (Malawi) Subject H\% and Gradual Declination 
Thus, for local effects, we see the use of boundary $\mathrm{H} \%$ and $\mathrm{L} \%$ to mark domains within an intonational phrase, including subjects, topics, and internal clauses (like relatives or complementiser clauses). The marking of internal domains by $\mathrm{H} \%$ suggests a continuation rise particularly used in demarcating information in cases of multiple clauses as we saw in the Shingazidja example in Figure 5. For Bemba which generally marks internal domains with a $\mathrm{L} \%$, it may be that the implementation difference between internal and final $\mathrm{L} \%$ is important to distinguish the two types of intonational events.

\section{Global Effects in Intonation}

Global effects contrast with local effects discussed above in being intonational effects that are sustained over a larger domain rather than just the edge of a domain. As we have seen with, for example, final lowering affecting only the right edge to mark a subject or a declarative clause. The two main global effects we will deal with are pitch range expansion and pitch range compression and their variations. Sentential downstep, or at least, downstep that applies over a long domain as already seen in Figure 3 is also a kind of global effect in that in holds over the rest of a domain once it is triggered.

\section{Pitch Range Expansion (PRE)}

Pitch Range Expansion (PRE) involves an increase in the F0 range of tone throughout a clause/specific domain. Cross-linguistically, PRE is widely seen in polar questions (Gussenhoven, 2004). ${ }^{13}$ In Bemba, we see PRE in polar questions (with or without an optional question particle bùshé) as a global effect. We will mark PRE with a left edge intonational tone $(-\mathrm{H})$ whose expansion effects is seen over the whole sentence. Let us consider the intonation of the following two polar questions, where the second includes a question particle at the beginning.

bànàmáàyó bá-ká-'péél-à 2woman 2sM-FUT3-give-FV

b. úmú'káátè?

3 bread
'The women will give the bread?'

bùshé ábáàná $\quad$ bá-ká-bíl-à
$Q \quad$ 2child $\quad$ 2sM-FUT3-sew-FV
'Q the children will sew the shorts?'
Q
'Q the children will sew the shorts?'

\footnotetext{
${ }^{13} \mathrm{~F} 0$ is fundamental frequency and technically, is the number of vocal fold vibrations (oscillations) per second measured in Hertz. F0 is what is perceived as pitch by the human ear. The adult F0 range is between 100-300Hz with females usually having a higher pitch range.
} 


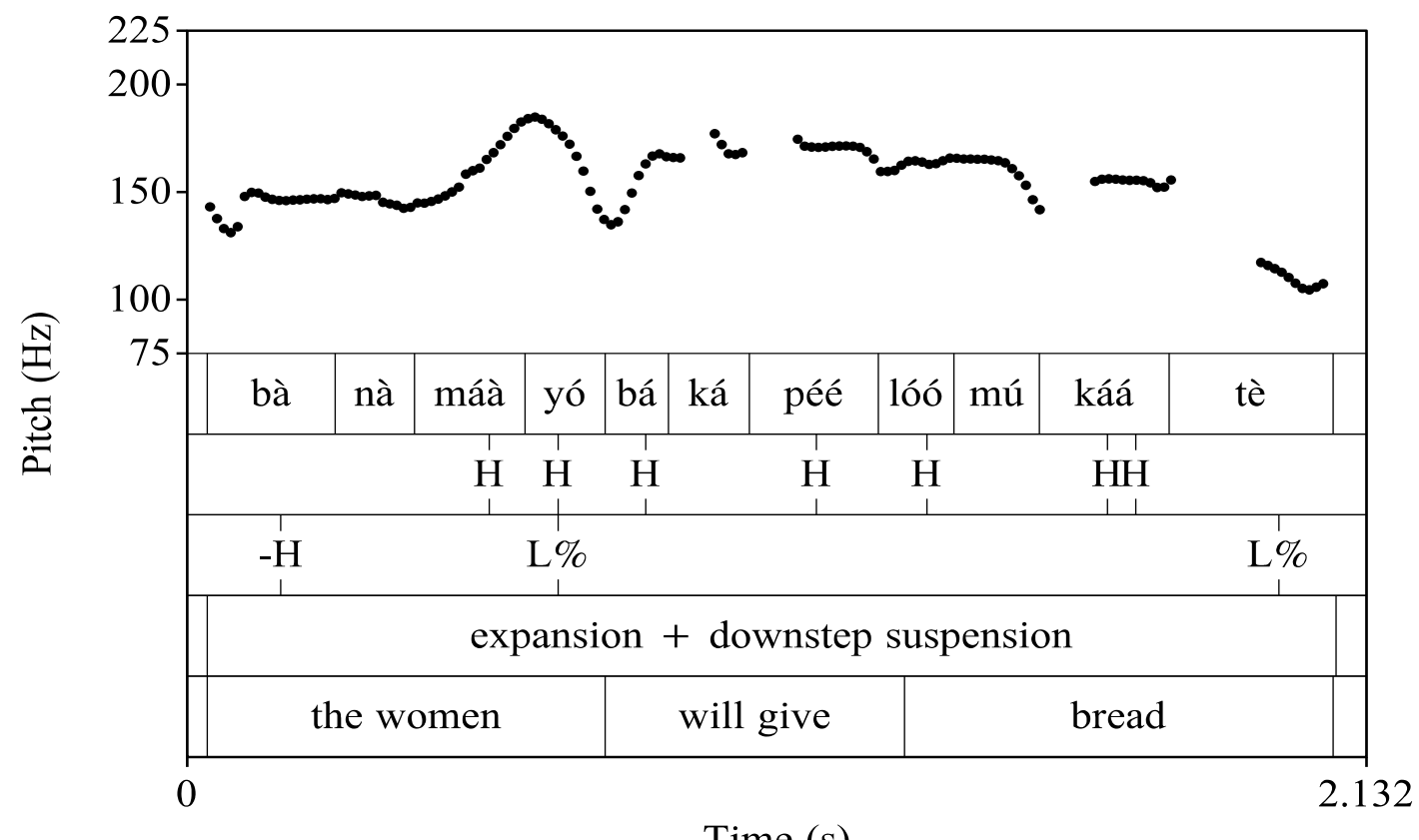

Time (s)

\section{Figure 7: Polar Question with PRE in Bemba}

The left edge intonational $-\mathrm{H}$ tone starts the F0 contour high and this goes even higher at the lexical tones but then shows a drop at the subject, marked by a boundary L\%. After that it resumes the expanded pitch range, sustaining this to the end of the sentence. We see two important effects at the end. There is still a boundary $\mathrm{L} \%$, contrasting with what we see in polar question for most Western languages, and also for Bemba, we do not see the nonpunctual implementation of the final $\mathrm{L} \%$ as we saw at the end of declaratives. This would support the saliency hypothesis as in this case, we are ending with important information for the interpretation of the utterance, that is the whole utterance is questioned. Thus, the central intonational feature used for polar questions is PRE but which still includes a subject $\mathrm{L} \%$ and also a final punctual $\mathrm{L} \%$. The intonational structure of $14 \mathrm{~b}$ is no different than that in Figure 7, although the rise seems to start even earlier in this case. However, here too, we see a fall at the subject and punctual implementation of the question final $\mathrm{L} \%$.

We can verify that polar questions do indeed have PRE by directly comparing the representation in Figure 7 with that of a declarative as in Figure 8 below. 


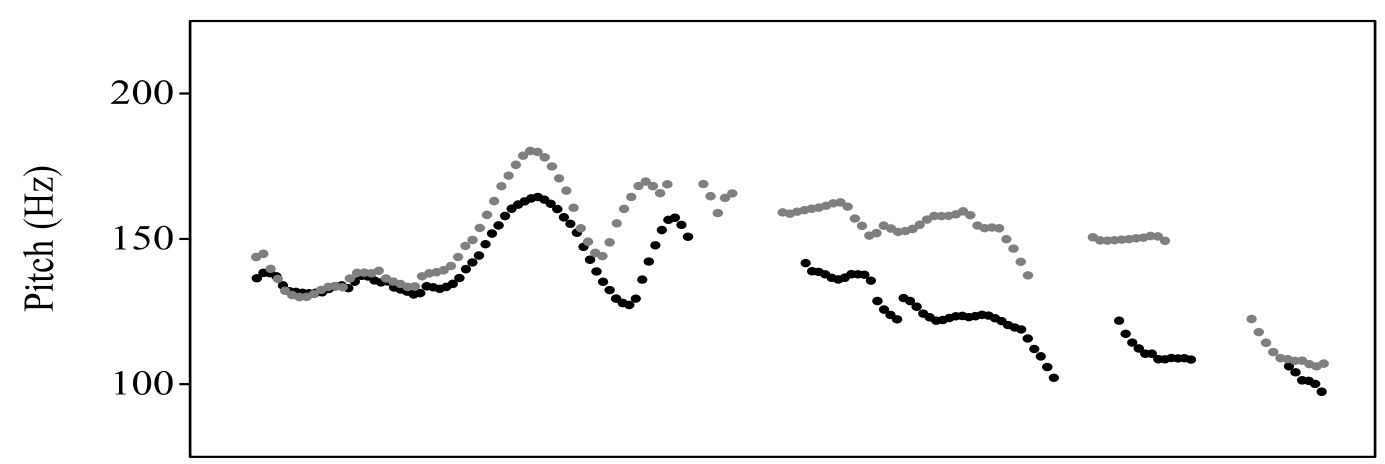

Normalized time

\section{Figure 8: bànàmạàyó bá-ká-'péeèl-à úmu'kááte 'The women will give bread' (Polar question in grey and declarative in black)}

The amount of expansion in the grey pitch track is clear to see, although the rise starts gradually, given that the beginning of utterances in any case start relatively high. The two sentences start at about the same point but the grey one stays higher, and towards the end, it is still high when the declarative has gradually already started implementing the L\% affecting the final few syllables. Notice also that the subject L\% is produced at a higher register in the expanded question. ${ }^{14}$ One important feature in polar questions that we do not see in this particular example is that downstep is suspended during expansion, so that its effect is totally diminished. We can then, in this sense, consider expansion to be more important to maintain in polar questions than downstep. ${ }^{15}$

By comparison to polar questions, constituent questions, so called 'wh-questions', show only partial PRE with the question word itself not receiving any prominence. This can again be related to discourse functions, since when a question word is present, it is less important to signal questioning with intonation, although this is not to say it is absent. It is just in this case not the most important feature. Consider the constituent question in 15 and its corresponding pitch track in Figure 9 below.

(15) abáàná bá-!mwééné bàànì kúsúkuùlù

2child 2SM-see.PRF who 16school

'Who did the children see at the school?'

14 Comparison in absolute terms of the declarative in Figure 1 and the polar question in Figure 7 shows that the declarative is produced just above $150 \mathrm{~Hz}$ throughout, while the polar question is very solidly around $185 \mathrm{~Hz}$ at least. This comparison here is possible since these are produced by the same speaker with the same pitch range of about $300 \mathrm{~Hz}$. See Clements (1990) for a discussion of register in intonation.

15 If we were OT prone, we would treat this as PRE being higher ranked than Downstep, at least, for polar questions. 


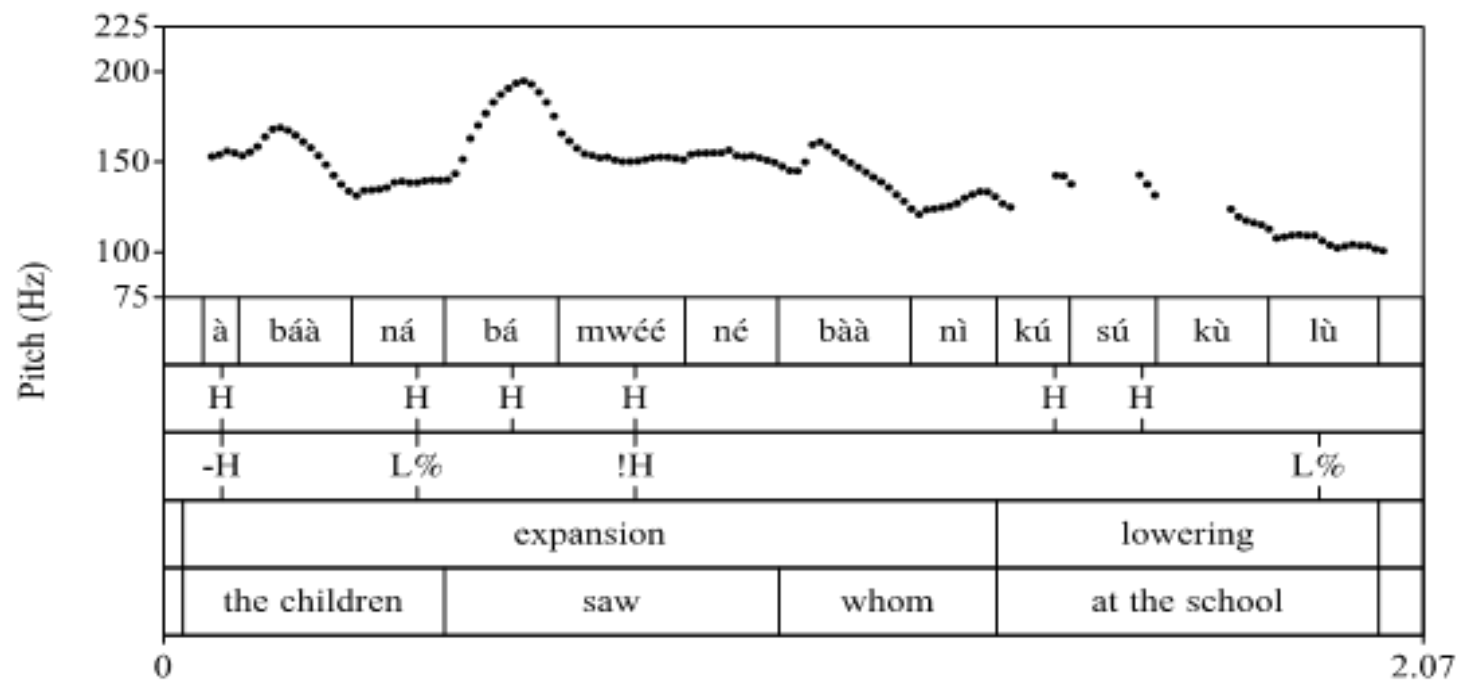

Time (s)

Figure 9: Constituent Question with Question Word 'baani' (who) in Bemba

The question starts at a regular pitch register and we see a boundary L\% at the subject (abaana 'children') and then we see more expansion at the start of the verb. In contrast to polar questions, in this case downstep is not suspended and, significantly, also affects the question word. This is significant because it means that the question word itself gets no prominence, again contrasting it with a number of Western languages. Based on the examination of a number of polar questions of this sort (indeed, 10 tokens of this sentence at least), in Kula and Hamann (2017) we assumed that the -H intonational tone is at the left edge of the sentence, since subjects start higher than in declaratives. I would, however, like to offer an alternative analysis here to have this -H at the start of the VP so that the target of expansion in constituent questions is smaller than in polar questions. Consider another example with what below. ${ }^{16}$

(16) bàkàfúndíshá bá-ø-sáámbílìsh-à ínshì lèèló
2teacher
'What does the teacher (usually) teach today?'

16 A perhaps more common way of asking the questions in (15-16) in Bemba is with a clefted question using at the start ni-baani. (It is who..) or ni-nshi.. (It is what..) in (15) and (16), respectively. Here the questions are presented with the question word in so-called 'in-situ' position. These are totally acceptable ways of asking these questions. 


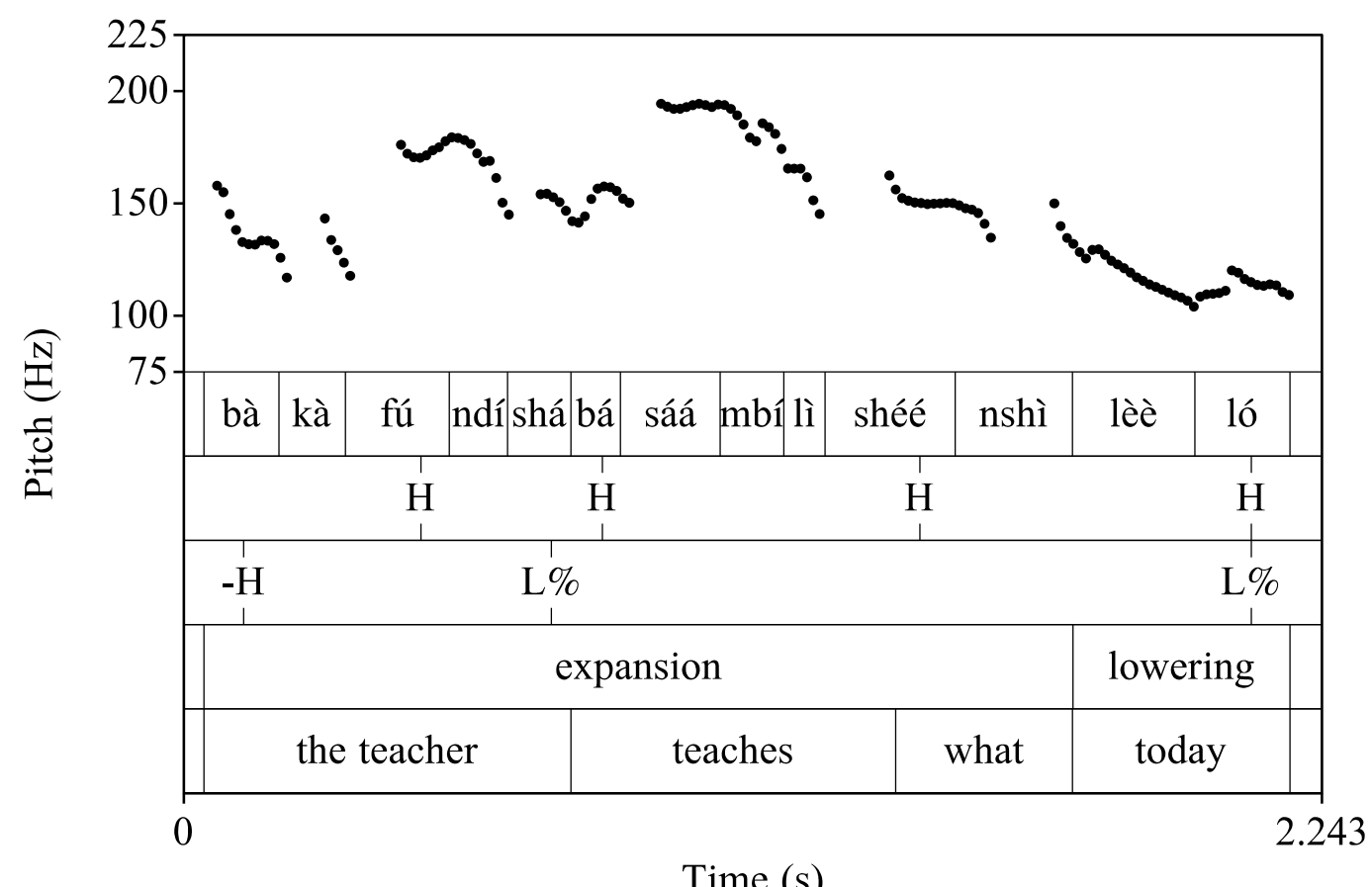

Figure 9: Constituent Question with Question Word 'inshi' (what) in Bemba

Figure 9 nicely contrasts with Figure 8 as it does not have a downstep in it and allows us to verify that the non-prominent question word in Figure 8 is not due to the downstep. Here also, we see expansion starting more at the left edge of the VP but is already falling at the question word and we again see the final $\mathrm{L} \%$ affecting more than just the final syllable. Constituent questions thus, contrast sharply with polar questions in Bemba in having non-punctual implementation of the boundary L\%, just like declaratives. But with the verb being as high as $200 \mathrm{~Hz}$ for this speaker, we clearly have PRE that we do not see in declaratives. We could consider that the presence of the question word signalling the intended message of the speaker, is what allows the intonation to not require prominence on the question word, but see the discussion of focus below showing that this is not quite sufficient.

This discussion of constituent questions brings us to the final PRE context we will investigate, namely; new information focus. Discussions of focus in Bemba can be found in Givón (1975); and in Costa and Kula (2008). The answer to a constituent information question generally provides new information that the questioner is seeking from the addressee. Although in such situations, it is much more natural to only give the single word/phrase that provides the new information, we consider here responses that give the whole sentence including those parts that are known. This allows us to investigate whether focused constituents, the new information in the sentence, gets specific intonation 
or prominence to signal its newness. Looking at the full sentence response also allows to see whether there are any specific intonational patterns in such utterances. Consider the question and answer pair in 17 below. Figure 10 gives the pitch track of only the response that contains the focus.
Q: bàkàfúndíshà bá-léé-ípík-à
ínshì lèèló
2teacher 2SM-PROG-cook-FV what today
'What is the teacher cooking today?'
A: bá-léé-ípíkà
ùbwáálí
lèèló
2SM-PROG-cook-FV
14ubwaali today
'He is cooking ubwaali today.'

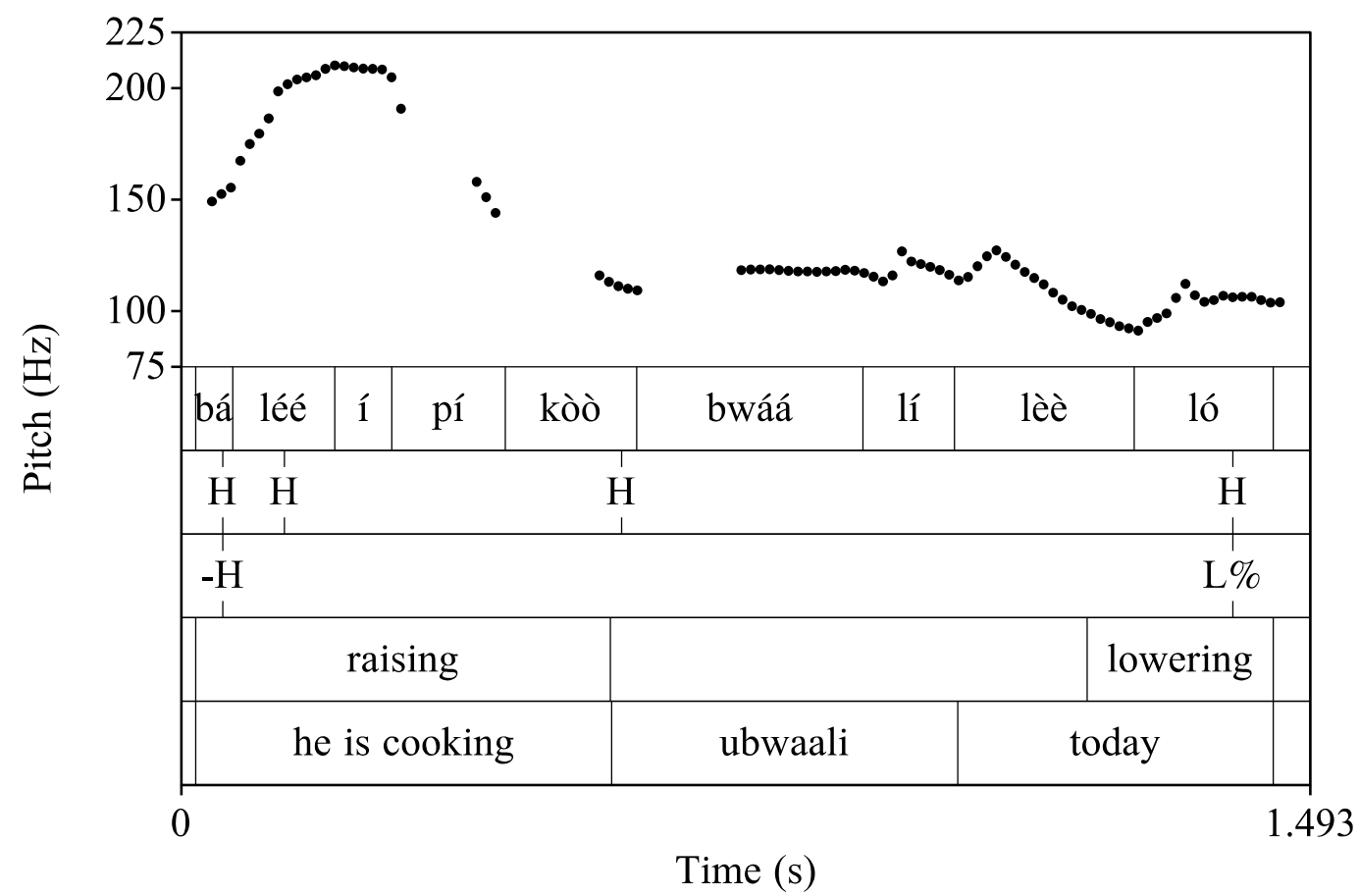

\section{Figure 11: Pre-focus Raising in Bemba (new information focus)}

There is an uncanny resemblance between this structure in Figure 11 and what we have seen for constituent questions: PRE starts at the left edge of the VP and is partial, that is not extending to the end of the domain, with the focused word ubwaali, also having no prominence just like the question word. As has been noted for a number of Bantu languages (see Zerbian, 2006, Downing, 2012, 2013, and also languages in the Downing and Rialland, 2017) volume), this is a significant departure from work in the literature on Western languages where generally, focused constituents show prominence. What is additionally interesting though in Bemba, is that there is pre-focus raising, just as we saw with question words which are also inherently focused. 
The fact that PRE, if we may call it as such in constituent questions and in focus constructions, does not extend over the whole domain to the right of the $-\mathrm{H}$ intonational tone, may suggest that it is less global than what we see in polar questions. It is for this reason that the term 'raising' is used, but more importantly this is a matter that will need to be further explored by ascertaining what the prosodic domain that this pre-focus raising marks or even that it only marks the left edge of such a prosodic domain (e.g. an intermediate intonational phrase) and by looking at other types of questions to see what intonational patterns occur there (see, Patin and Riedel, 2011 for good discussion of different question types that can be considered). ${ }^{17}$

\section{Pitch Range Compression (PRC)}

Contrasting with PRE, PRC involves a severe reduction in the F0 range. This is usually in cases involving dislocation, where constituents in a sentence are moved away from their canonical position to the right or left edge of the phrase. Cheng and Downing (2009) provide discussion on the relation between topics and dislocation. In Bemba, we see this in the right dislocation of subjects and objects. Pitch Range Compression is a global effect because it affects the whole dislocated constituent. We will denote this with $-\mathrm{L}$ preceding the right dislocation. Consider the object right dislocation sentence in $18 \mathrm{~b}$ derived from 18a below and its pitch track representation in Figure 12.

$\begin{array}{lll}\text { a. bá-lá-'bélééng-á ì̀cítábó } & \text { bwínó } \\ \text { 2SM-HAB-DJ-read-FV } & 7 \text { book } & \text { well }\end{array}$

'They read the book well'

b. bá-lá-!bélééng-á bwínó ìcítábó

2SM-HAB-DJ-read-FV well 7book

'They read well, the book (that is)'

18a gives the canonical position of the object as following the verb, with the adverb following the object. In $18 \mathrm{~b}$ we can verify that the object is dislocated because it occurs after the adverb and is in this sentence an afterthought, indicated by adding 'that is' in the gloss. In the pitch track of $18 \mathrm{~b}$ below, we see that the object is totally compressed.

There are pertinent discussions on questions in Sabel and Zeller (2006) as well as the seminal work of Rialland $(2007,2009)$ on question prosody in African languages more broadly, that provide important insight to investigating questions. 


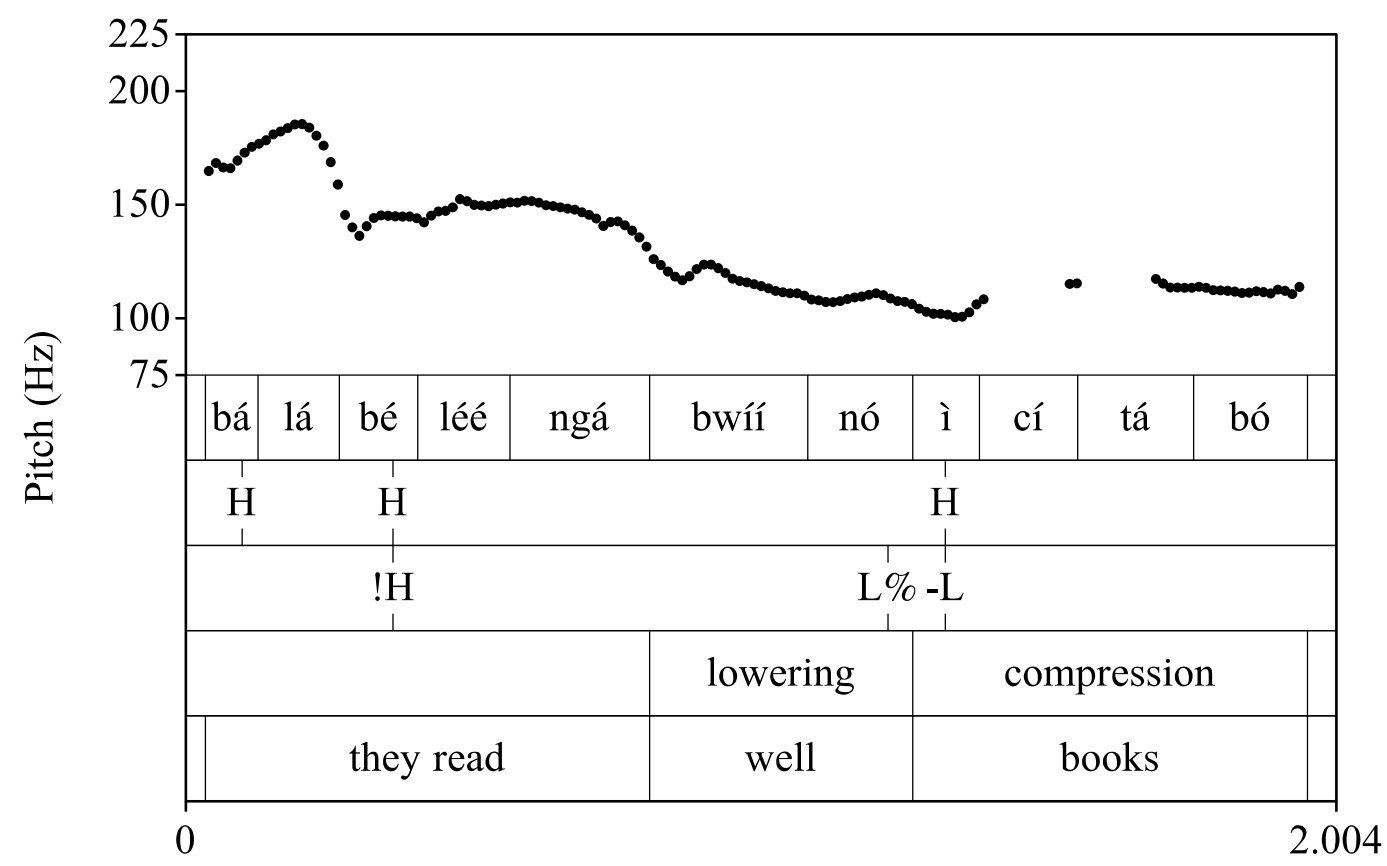

Time (s)

\section{Figure 12: Right Dislocated Object in Bemba with Compression}

Figure 12 shows that the end of the main clause is marked with a boundary L\% as would be expected, with the adverb bwínó (with all lexical Hs) showing lowering. The object that then follows is compressed, although it has three H-toned syllables. Compression is indicated by the left edge boundary $-\mathrm{L}$ and is seen to affect the whole object. The verb in this case also shows downstep that is sustained until final lowering begins. The same compression applies to right dislocated subjects.

Left dislocated constituents are topics, and from what we saw above, these behave like subjects in showing a boundary L\% after them. Because Bantu languages are pro-drop languages, that is they can drop their subjects with the subject marked pronominally on the verb through subject markers, it is not so easy to distinguish subjects from topics (see the classic work on this distinction in Bresnan and Mchombo, 1987) and from the current distribution, it appears that subjects and topics show similar intonation, (that is they are marked by a boundary L\%, but see Cheng and Downing, 2009) for cases where these can be prosodically distinguished. There is, however, contrasting data for object topics where one of two speakers showed a boundary (continuation $\mathrm{H} \%$ ) after an object topic. More investigation must be conducted on this before any substantive conclusions can be made.

\section{Discourse Functions in Global Effects}

From the distribution of PRE vs. PRC, we can see the role of discourse saliency: PRE is associated with saliency in contributing to the interpretation of the utterance, while PRC 
is associated with discourse of old information that consists of afterthoughts. However, at least for PRE in focus constructions (including constituent questions), the expansion is not on the discourse salient constituent itself. This means it is not on the focused word or the question word itself, rather there is a cue prior to the focus to signal the coming salient category. There is a direct correlation between the kind of PRE used and how the final boundary L\% is implemented. When PRE is global, affecting the whole utterance as in polar questions, then boundary L\% implementation is punctual. By contrast, when PRE is partial (pre-focus raising) then implementation of the boundary L\% is non-punctual and stretches over the last few syllables. The contrast between global and partial PRE may also explain why downstep cannot be suspended in polar questions where the whole utterance is salient in the discourse and, therefore, all expanded. Pitch Range Compression, by its very nature, does not allow us to see a final $\mathrm{L} \%$ which is obviated in this context.

To summarise global effects in Bemba, PRE is seen in polar questions with a punctual final L\% indicating an intonational phrase (IP). Constituent questions and focus do not have global PRE but show partial pre-focus raising. Polar questions, on the one hand, and constituent questions and focus constructions, on the other hand, contrast in the application of downstep where it is suspended in the former but allowed to apply in the latter contexts. There is no punctual implementation of the right edge boundary L\% in questions and focus.

\section{Eastern Bantu Comparative Data on Global Effects}

We will compare our four languages in this study on the global effect parameters we have discussed for Bema, namely; PRE in polar questions; application of downstep in polar questions; constituent/content questions; application of downstep in content questions, and focus constructions. We will not consider PRC as there is no comparable data but also we can probably safely assume that when PRC occurs, it will be fairly uniform with the more interesting question being whether there is a contrast between right and left dislocation in Eastern Bantu.

A summary is given in Table 2 below. Overall, there is no uniform application of PRE across the four languages. The application of downstep is uniform in all cases with downstep suspended in polar questions but not in content questions. Significantly, and as has come to be the pattern across Bantu, focus is not prosodically marked by prominence on the focused constituent. 


\begin{tabular}{|c|c|c|c|c|}
\hline $\begin{array}{l}\text { Intonational } \\
\text { cue }\end{array}$ & Bemba & Shingazidja & Chichewa & Tumbuka \\
\hline $\begin{array}{l}\text { PRE in Polar } \\
\text { questions }\end{array}$ & $\begin{array}{c}\text { Yes (left edge } \\
-\mathrm{H})\end{array}$ & $\begin{array}{l}\text { No }-\mathrm{LH}^{*}+ \\
\mathrm{L} \% \text { (super } \mathrm{H} \text { on } \\
\text { penult) }\end{array}$ & No - LHL \% & No - LHL \% \\
\hline $\begin{array}{l}\text { Downstep in } \\
\text { polar questions }\end{array}$ & $\begin{array}{c}\text { No - } \\
\text { suspended }\end{array}$ & No - suspended & No- suspended & No - suspended \\
\hline $\begin{array}{l}\text { PRE in content } \\
\text { questions }\end{array}$ & $\begin{array}{l}\text { Yes - PRR } \\
\text { (not on qn. } \\
\text { Word) }\end{array}$ & $\begin{array}{l}\text { No - final } \\
\text { shallow rise }\end{array}$ & No & No - final rise \\
\hline $\begin{array}{l}\text { Downstep } \\
\text { in content } \\
\text { questions }\end{array}$ & Yes & Yes & Yes & Yes \\
\hline $\begin{array}{l}\text { Final lowering } \\
\text { at the end of } \\
\text { qns }\end{array}$ & Yes L\% & $\begin{array}{c}\text { No - final } \\
\text { shallow rise }\end{array}$ & Yes L\% & $\begin{array}{c}\text { Yes } \mathrm{L} \% \text { for } \\
\text { polar questions } \\
\text { but } \mathrm{H} \% \text { for } \\
\text { content qns }\end{array}$ \\
\hline $\begin{array}{l}\text { Prominence on } \\
\text { focus }\end{array}$ & $\begin{array}{c}\text { No - pre- } \\
\text { focus raising }\end{array}$ & $\begin{array}{l}\text { No - cued by } \\
\text { phonological } \\
\text { phrasing }\end{array}$ & $\begin{array}{l}\text { No - emphasis } \\
\text { prosody instead }\end{array}$ & $\begin{array}{l}\text { No - emphasis } \\
\text { prosody instead }\end{array}$ \\
\hline $\begin{array}{l}\text { PRE or PRR } \\
\text { elsewhere in } \\
\text { focus }\end{array}$ & $\begin{array}{l}\text { Yes - PRR } \\
\text { (pre-focus } \\
\text { raising) }\end{array}$ & No & No & No \\
\hline
\end{tabular}

Let us consider a few cases from the above for illustration. While we saw PRE in Bemba, and gave this a fitting natural explanation as indicating saliency, this does not apply in the other three languages. In Shingazidja, there is a super $\mathrm{H}$ on the penult marked by the intonational accent $\mathrm{LH}^{*}$ which is then followed by a final $\mathrm{L} \%$ so that polar questions are marked by the complex intonational tone $\mathrm{LH}^{*}+\mathrm{L} \%$. This is illustrated in Figure 13 below drawn from Patin (2017). 


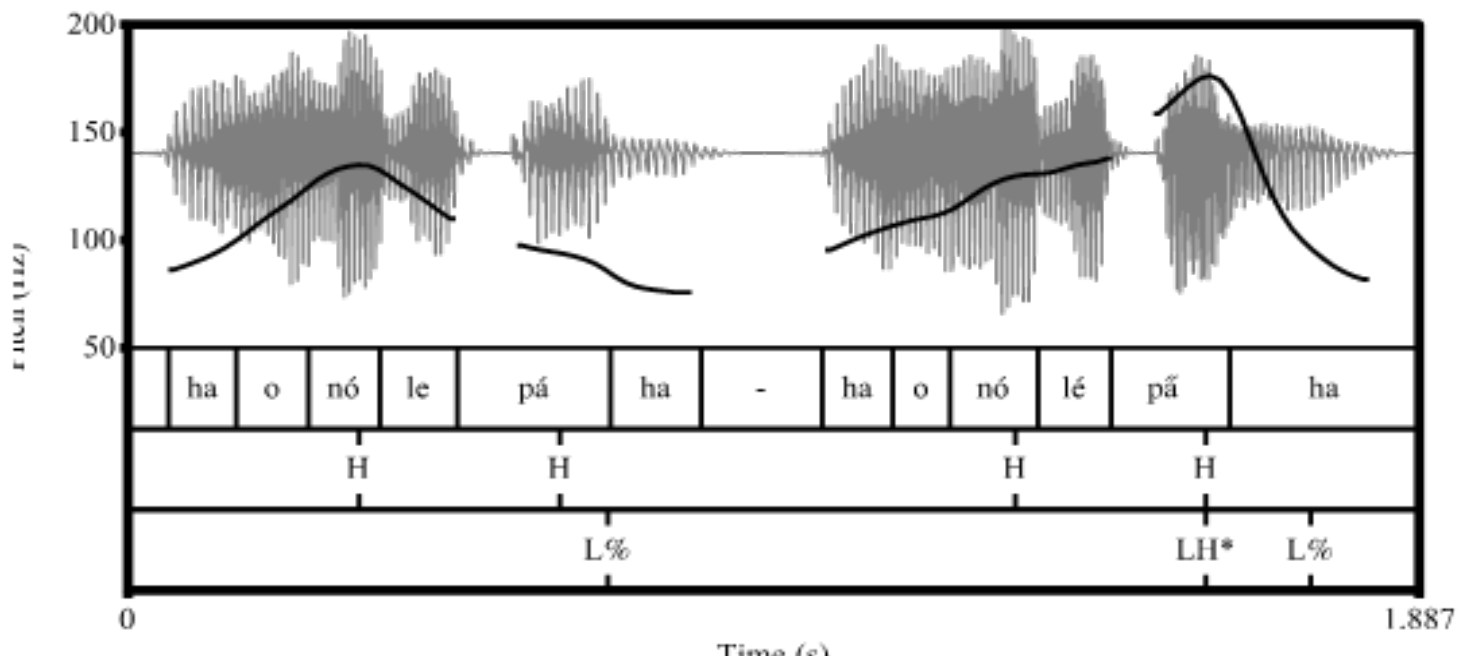

Time (s)

'He saw the cat'

'Did he see the cat?'

\section{Figure 13: LH*+L\% Marking a Polar Question in Shingazidja (Moroni dialect)}

The representation in Figure 13 shows the pitch track of two sentences, the first is a declarative and the second is the polar question. The contrast in the intonation is that the question starts quite low and builds up to the $\mathrm{LH}^{*}$ on the penult and then falls at the end to the $\mathrm{L} \%$, showing that the $\mathrm{LH}^{*}$ is the significant intonational event marking a polar question in Shingazidja. There is no overall PRE as we saw in Bemba, indeed we can question whether the marking of polar questions in Shingazidja involves a global effect at all, but see discussion below. Chichewa also shows no other significant events in the intonation of polar questions other than a final LHL\% (See Figure 14 below).

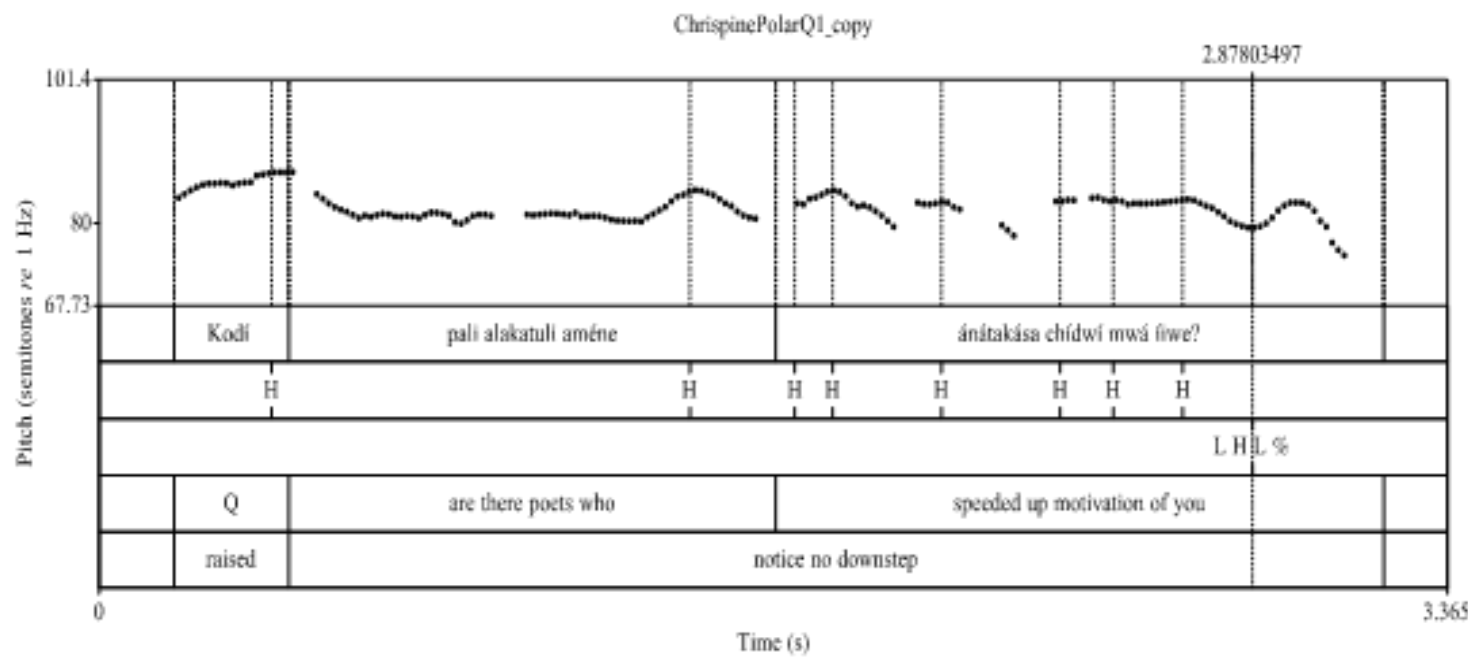

Figure 14: Chichewa (Malawi) Polar Question Ending with LHL\% 
Like in Bemba, the Chichewa polar question in Figure 14 has an initial (optional) question particle kodi. The intonation then follows what we might expect in a declarative but crucially, we see no downstep where we might expect it between the adjacent lexical Hs, with the significant event being the final LHL\%. A similar pattern is also seen in Tumbuka. Thus, although there is no PRE in any of Shingazidja, Chichewa and Tumbuka, there is, nonetheless, suspension of downstep showing that the buildup to the right edge effect marked by LHL\% must dominate the utterance as the main event. Thus, while the implementation of the LHL \% is local to the right edge, it has an effect on a wider domain - the whole polar question - disqualifying the application of downstep.

For constituent questions, Chichewa patterns with Bemba show no prominence on the question word and also the same non-prominence on a focus as the pitch tracks in Figure 15 show. The left hand panel shows the question with the question word chiyáani 'what' showing no prominence, with declination to final lowering already started. Notice though that there is some raising after the subject, more than we see, for example, in Figure 14 or Figure 6 for Chichewa. The right panel shows the answer to the question where nyuúmba 'house' is new information but also does not show any prominence. In both panels, there is pitch reset after the subject but this appears to be higher than we have seen earlier and this would be something to investigate in future work.

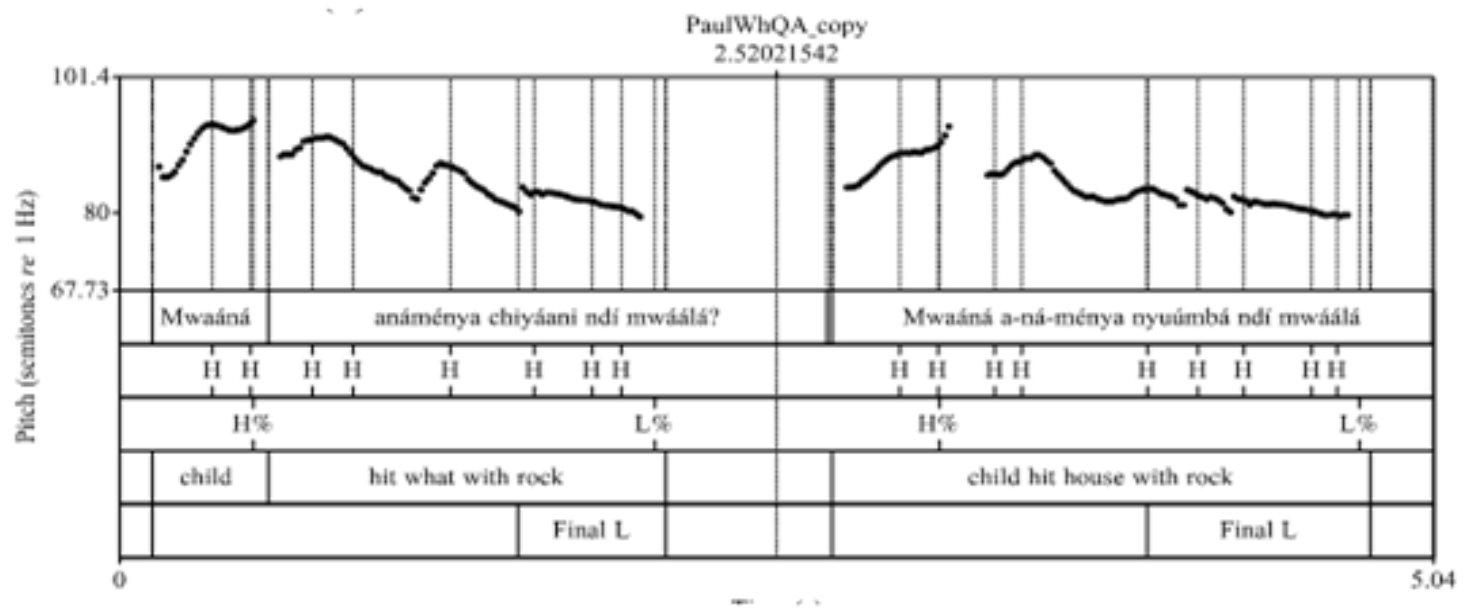

\section{Figure15: Content Question and Answer (New Information Focus) in Chichewa (Malawi)}

Shingazidja and Tumbuka pattern differently from Bemba and Chichewa in that they show a final rise in content questions. We can see this in Figure 16 below for Tumbuka, where the question word vil'cil 'what' shows a raised final. 


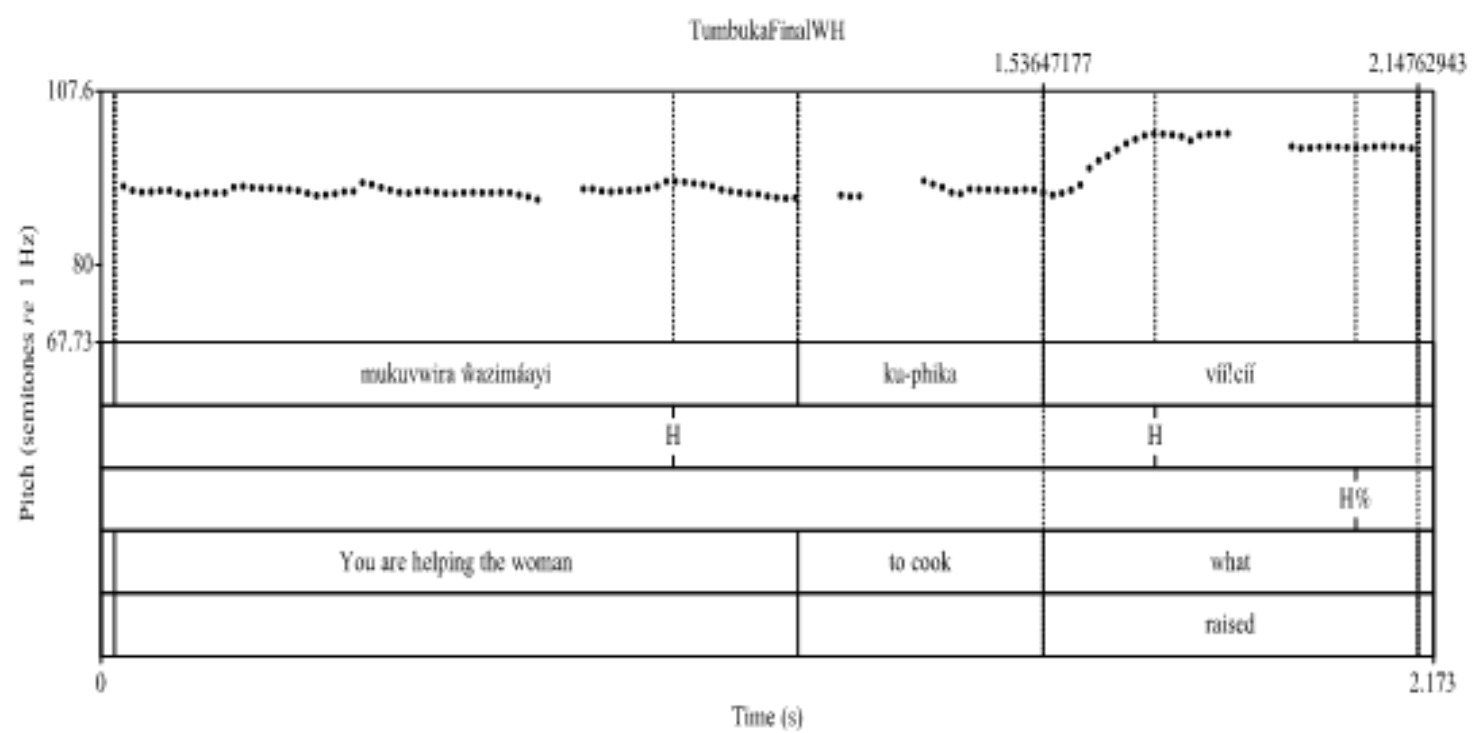

\section{Figure16: Content Question with Raised Final in Tumbuka (Malawi)}

Rather than PRE, we see a rise only on the final question word in Tumbuka that Downing (2017) marks with a final boundary $\mathrm{H} \%$. The uniform pattern seen between constituent questions and polar questions is that in the former, downstep still applies. There may, thus, be an overall localised interpretation of intonational events in constituent questions that does not hold in polar questions, which makes downstep permissible in this case.

Directly related to questions are focus constructions on which all languages are uniform in showing no prosodic prominence on the focused constituent. We have already seen this for Bemba and Chichewa. Tumbuka, also like Chichewa has what Downing, (2017) terms as some emphasis prosody that is associated with focus but which is not to be interpreted as an increase in F0. For Shingazidja phonological phrasing is the main cue for focus, with a focused constituent usually within the same phonological phrase as the verb thus contrasting structures like (VP O $)_{\mathrm{PP}}$ as having focus on the object, and $\left[(\mathrm{VP})_{\mathrm{PP}}\right.$ $\left.(\mathrm{O})_{\mathrm{PP}}\right]$ as having focus on the verb. This is similar to what we saw briefly also for Bemba in Section two.

A final feature that all the languages compared share is final lowering and this is seen to apply also in questions, particularly in polar questions. Only in constituent questions in Shingazidja and Tumbuka do we see final lowering not surfacing in all the structures investigated. What emerges overall is some common patterns but also some contrasting patterns which help us to identify what areas we may expect to see variation in, even amongst geographically close Bantu languages.

\section{Emerging Features in Eastern Bantu and Conclusions}

The foregoing discussion offering a comparison of the intonation of four Eastern Bantu languages has allowed us to begin to consider what features are emerging in the relatively recent more in-depth work on the intonation of Bantu and African languages more broadly. The goal of the paper was to find areas of similarity but also those for which we can see 
and develop parametric variation with a specific focus on events within an intonational utterance - looking at both local and global effects - with less attention paid to the internal structure of the intonational phrases. We have thus, not covered questions to do with how the different levels of the prosodic hierarchy are represented, whether right or left edges are more dominant in those representations and also what the mapping between syntax and phonology is in internal structures (see Truckenbrodt, 1999, Kula, 2007, for some discussion).

Within intonation we are generally, dealing with the highest level of the prosodic hierarchy, that is the intonational phase. Therefore, the question is one of whether there are smaller intonational domains within larger ones. These smaller internal intonational phrases - intermediate intonational phrases - are generally, considered to be larger than phonological phrases, which as we saw for Bemba can also be domain of lexical tone spreading. Some of the local effects we have discussed have been indicative of these intermediate intonational phrases (for example, subject boundary tones) and there is evidence that these structures can be recursive at least, in Bemba. A summary of how the effects we have discussed map onto intonational phrases in the table below for Bemba are given. This allows us to see more broadly the kinds of mappings involved in intonation and how this relates to the domains that may be cued in syntax by intonation, explaining how it is that intonation allows us to processes long stretches of speech into meaningful units to which we can then map meaning in order to aid communication. In the table below, intermediate intonational phrase are the same as minimal intonational phrases. Maximal intonational phrases refer to the largest or outermost intonational phrase covering the whole utterance. In general, min and max phrases interact with syntax minimally by referring or aligning only to the edges of syntactic constituents as exemplified below (see some specific proposals in Selkirk, 2011). 


\begin{tabular}{|c|c|c|c|}
\hline STRUCTURES & $\begin{array}{l}\text { INTONATIONAL } \\
\text { EFFECTS }\end{array}$ & SYNTACTIC EDGE & $\begin{array}{l}\text { Prosodic } \\
\text { DoMaIn }\end{array}$ \\
\hline \multirow[t]{2}{*}{ DECLARATIVES } & $\begin{array}{l}\text { L\% after subject } \\
\text { (optional pause) }\end{array}$ & RIGHT XP & minimal i-phrase \\
\hline & L\% (final lowering) & RIGHT CP & maximal i-phrase \\
\hline \multicolumn{4}{|l|}{ SUBORDINATES } \\
\hline \multicolumn{4}{|l|}{$\begin{array}{l}\text { a) Preverbal } \\
\text { topics }\end{array}$} \\
\hline - clausal topic & $\mathrm{L} \%$ & RIGHT CP & maximal i-phrase \\
\hline $\begin{array}{l}\text { - non-clausal } \\
\text { topic }\end{array}$ & $\mathrm{H} \%$ (continuation) & RIGHT XP & minimal i-phrase \\
\hline $\begin{array}{l}\text { - contrastive } \\
\text { topics }\end{array}$ & $1^{\text {st }}$ topic $-\mathrm{H} ; \mathrm{L} \%$ & $\begin{array}{l}\text { LEFT XP ; } \\
\text { RIGHT XP }\end{array}$ & minimal i-phrase \\
\hline \multicolumn{4}{|l|}{ b) Dislocations } \\
\hline - RD subject & $\begin{array}{l}-\mathrm{L} \text { (pitch range } \\
\text { compression) }\end{array}$ & LEFT XP & maximal i-phrase \\
\hline - RD object & $\begin{array}{l}-\mathrm{L} \\
\text { (pitch range } \\
\text { compression) }\end{array}$ & LEFT XP & maximal i-phrase \\
\hline \multicolumn{4}{|l|}{ QUESTIONS } \\
\hline a) polar questions & $\begin{array}{l}-\mathrm{H} ; \mathrm{L} \% \\
\text { (pitch range expansion) }\end{array}$ & $\begin{array}{l}\text { LEFT CP ; } \\
\text { RIGHT CP }\end{array}$ & maximal i-phrase \\
\hline $\begin{array}{l}\text { b) constituent } \\
\text { questions }\end{array}$ & $\begin{array}{l}-\mathrm{H} ; \mathrm{L} \% \\
\text { (partial pitch } \\
\text { expansion) }\end{array}$ & $\begin{array}{l}\text { LEFT CP } \\
\text { RIGHT CP }\end{array}$ & maximal i-phrase \\
\hline c) focus & $\begin{array}{l}-\mathrm{H} ; \mathrm{L} \% \\
\text { (partial pitch } \\
\text { expansion/pitch } \\
\text { raising) }\end{array}$ & $\begin{array}{l}\text { LEFT XP ; } \\
\text { RIGHT CP }\end{array}$ & $\begin{array}{l}\text { minimal } \\
\text { i-phrase?; } \\
\text { maximal i-phrase }\end{array}$ \\
\hline
\end{tabular}

Table 3: The Mapping of Intonational Cues to Prosodic Structure and to Syntax in Bemba 
We have seen an interesting range of intonational effects that show similarities and contrasts that are instructive in understanding intonational features of Eastern Bantu. The features we have focused on which provide initial areas of symmetry centre around the following potential areal features:

(i) Intonation of content questions - No global PRE, nor on the question word

(ii) Intonation of focus constructions - No PRE on the focus

(iii) Implementation of boundary $\mathrm{H} \%$ - seen in most internal clauses

(iv) Final Lowering - in most declaratives and $\mathrm{L} \%$ at the end of the questions

(v) Penultimate lengthening - its presence or absence may signal particular intonational effects

These broad areas, as has been shown in the foregoing, can be investigated with respect to a number of specific features which are provided in the appendix below as a diagnostic tool for the initial investigation of the intonation of Bantu languages. It is hoped that this will contribute to facilitating the study of a wider set of languages to refine our understanding of the limits and parameters of intonational patterns across Bantu languages. In future research, in advancing the understanding of intonation in Bantu languages, different pragmatic contexts, such as the role of saliency as has been briefly noted, that bring us to a fuller understanding of the many intonational nuances that speakers use to express various different emotions in everyday communication can be probed.

\section{Appendix \\ Intonation Diagnostic Protocol/Questionnaire}

The following questions provide some guidance on areas that can be probed in an initial investigation of intonation in Bantu languages. Some understanding of the basic tone patterns of the language are useful, or at least, an ability to choose and identify words that end or start in a $\mathrm{H}$ or a L lexical tone is needed. This is to contrast these in similar contexts to tease out what may be an intonational versus a lexical tone effect.

\section{Lexical Tone and Segmental Effects}

(i) Is there lexical tone in the language?

(ii) If yes, is it a $\mathrm{H}$ vs. $\varnothing$ or $\mathrm{H}$ vs. L or $\mathrm{H}$ vs. L vs. Ø, or a hybrid/accentual system?

(iii) What tone is active in spreading? $\mathrm{H}$ only or both $\mathrm{H}$ and L? Are there contour tones?

(iv) What are the basic tonal properties/patterns of nouns and verbs? (Is there previous work/grammars that already describe this?)

(v) In all cases below, is there any interaction between lexical tone and intonational tone?

(vi) Is there penultimate lengthening? If yes, does this play a role in intonation or marking larger than word domains? 
(vii) Does the penultimate position attract a particular tone? And does it play a role in marking larger than word domians?

\section{Declaratives}

(2) Is there final lowering (FL) at the end of declaratives?

(2i) Is there declination (gradual fall in pitch) at the end of a declarative?

(2ii) If there is no FL how are declaratives marked? Is this done consistently?

(2iii) If there is FL how is it implemented? Punctual or non-punctual?

(2iv) Is there a distinction in the types of prosodic units for which punctual vs. nonpunctual implementation is used?

(2v) Are there discourse functions associated with the implementation?

(3) Do subjects get their own distinct intonation?

(3i) If yes, is this affected by the size of the subject?

(4) Does length of an utterance play a role in how the end is marked?

(4i) How are internal clauses with a longer utterance marked? How does this compare to list intonation?

Are all lexical tones in the language affected by final lowering? Or by, however, the end of a declarative is marked?

\section{Questions}

(6) How are questions marked?

(6i) If they show lowering, how do they differ from declaratives? Is there FL in questions?

(6ii) How are different kinds of questions marked in intonation considering:

- Polar questions

- Content questions: subject, object, adverbial questions

- Embedded questions

- Echo questions

- Multiple questions

- Cleft questions

(6iii) Do question words get specific intonational marking?

(6iv) Do questions show PRE? Does register play a role in the production of questions? Can there be partial PRE if it occurs?

(6v) How does question intonation compare to the answers to the questions?

Focus

(7) How is focus marked? 
(7i) How are different kinds of focus marked considering for example,

- New information focus

- Contrastive focus

- Alternative focus

- Corrective focus

- Presentational focus

- Broad vs. narrow focus

(7ii) Does the focused constituent get specific intonation? For example, prominence or is there pre- or post focus prominence?

(7iii) Does focus show PRE? Does register play a role in the production of focus?

(7iv) Does focus and question intonation differ? If yes, in what way?

\section{Downstep}

(8) Is there downstep in the language?

$8 \mathrm{i} \quad$ If yes, is it automatic or non-automatic downstep or both?

8ii Is there sentential downstep?

8iii If sentential downstep is present, is this maintained or suspended in:

- Questions

- Focus constructions

- Other construction types

\section{Topics, Clefts, Dislocations, Backgrounded Information}

(9) How are topics marked?

(9i) Does the intonational marking of topics differ from subjects?

(9ii) How are clefts marked? Does the intonational marking of clefts differ from topics and/or subjects?

(9iii) Is there both right and left dislocation? Do both show the same intonation pattern such as PRC?

(9iv) Is the phrasing of the dislocated constituent with the main clause on the right or left edge symmetrical or asymmetrical?

$(9 \mathrm{v})$ Is there specific marking for backgrounded information? Does this differ from dislocations?

Is it possible to stack topics and dislocations before the subject? What intonation do such structures show? 
(10) What is the intonation marking in specific constructions such as:

- Restrictive and non-restrictive relative clauses

- Adverbial clauses

- Complementiser caluses

- Coordinated clauses

- Clauses with ellipsis

(10i) Do these structures show recursivity?

(10ii) For all structures considered, what intonational phrases do they map to? Are there minimal/intermediate versus maximal intonation phrases? 


\section{References}

Batibo, H.M. (1976). A New Approach to Sukuma Tone, in Hyman, L.M. (ed.) Studies in Bantu Tonology. Southern California Occasional Papers in Linguistics 3.

Batibo, H.M. (1991). The Tone Structure of Sukuma Nominal Forms. Afrikanistische Arbeitspapiere (AAP) 25: 31-54.

Bickmore, L., and Kula, N.C. (2013). Ternary Spreading and the OCP in Copperbelt Bemba. Studies in African Linguistics 42(2): 101-132.

Boersma, P. and Weenink, D. (2014). Praat: Doing Phonetics by Computer. Version 5.4, Retrieved on 6 November 2014 from http://www.praat.org/.

Bolinger, D. (1978). Intonation Across Languages, in J.H. Greenberg (ed.) Universals of Human Language 2 (Phonology). Stanford: Stanford University Press, pp. 471- 524.

Bresnan, J., and Mchombo, S. (1987). 'Topic, Pronoun, and Agreement in Chichêwa.' Language 63: 741-782.

Buering, D. (2012). 'Focus and Intonation,' in Russell, G., and Fara, D.G. (eds.) The Routledge Companion to the Philosophy of Language. London: Routledge, 103-115.

Chebanne, A., Creissels, D., and Nkhuwa, H. (1997). Tonal Morphology of the Setswana Verb. LINCOM Europa.

Cheng, L., and Downing, L.J. (2009). Where's the Topic in Zulu? Linguistic Review 26: 207-238.

Clements, G.N. (1979). The Description of Terraced-level Tone Languages. Language 55: $536-558$.

Clements, G.N., and Ford, K.C. (1979). 'Downstep in Kikuyu.' Linguistic Inquiry 10: 179-210.

Clements, G.N. (1990). 'The Status of Register in Intonation: Comments on the Paper by Ladd and by Inkelas and Leben,' in Kingston, J., and Beckman, M.E.(eds.) 1990. Papers in Laboratory Phonology I: Between the Grammar and Physics of Speech, 5871.

Connell, B. (2001). Downdrift, Downstep, and Declination. Typology of African Prosodic Systems Proceedings.

Costa, J., and Kula, N.C. (2008). 'Focus at the Interface: Evidence from Romance and Bantu,' in Ceclie de Cat and Katherine Demuth, eds. The Bantu-Romance Connection: A Comparative Investigation of Verbal Agreement, DPs, and Information Structure. Amsterdam: John Benjamins, 293-322.

Cruttenden, A. (1997). Intonation. ( $2^{\text {nd }}$ edition). Cambridge: Cambridge University Press.

Downing, L.J. (2017). 'Tone and Intonation in Chichewa and Tumbuka,' in Downing, L. J., and Rialland, A. (eds.) Intonation in African Tone Languages. Berlin/New York: Mouton de Gruyter, 365-392. 
Downing, L.J. (2012). 'On the (non-)Congruence of Focus and Prominence in Tumbuka,' in Nikki, A., Marlo, M., Purvis,T., and Morrison, M. (eds.), Selected Proceedings of the $42^{\text {nd }}$ Annual Conference on African Linguistics. Somerville, MA: Cascadilla Proceedings Project, 122-133.

Downing, L.J. (2013). 'Rethinking the Universality of the Stress-Focus Correlation,' in Legère, K. (ed.) Bantu Languages and Linguistics: Papers in Memory of Dr. Rugatiri D. K. Mekacha. Bayreuth African Studies, Vol. 91: 47-67.

Downing, L.J. (2008). 'Focus and Prominence in Chichewa, Chitumbuka and Durban Zulu.' ZAS Papers in Linguistics 49: 47-65.

Downing, L.J. (2006). 'The Prosody and Syntax of Focus in Chitumbuka.' ZAS Papers in Linguistics 43: 55-79.

Downing, L.J., Mtenje, A., and Pompino-Marschall, B. (2004). 'Prosody and Information Structure in Chichewa.' ZAS Papers in Linguistics 37: 167-186.

Downing, L.J., and Rialland, A. (eds.) (2017). Intonation in African Tone Languages. Berlin/New York: Mouton de Gruyter.

Frascarelli, M. (2000). The Syntax-Phonology Interface in Focus and Topic Constructions in Italian. Dordrecht: Kluwer Academic Publishers.

Givón, T. (1972). 'Studies in ChiBemba and Bantu Grammar.' Studies in African Linguistics. Supplement 3.

Givón, T. (1975). 'Focus and the Scope of Assertion: Some Bantu Evidence.' Studies in African Linguistics 6.2: 185-205.

Gussenhoven, C. (2004). The Phonology of Tone and Intonation. Cambridge: Cambridge University Press.

Guthrie, M. (1945). The Tonal Structure of Bemba. Unpublished PhD Thesis, SOAS, University of London.

Hamann, S., and Kula, N.C. (2015). 'Bemba.' Journal of the International Phonetic Association 45.1: 61-69.

Hyman, L.M. and Monaka, K.C. (2008). 'Tonal and Non-Tonal Intonation in Shekgalagari.' UC Berkeley Phonology Lab Annual Report (2008), 269-288.

Kabinga, M. (2010). A Comparative Study of the Morphosyntax and Phonetics of Town Bemba and Standard Bemba of the Copperbelt, Zambia. MA Thesis, University of Cape Town.

Kashoki, E.M.(1968). A Phonemic Analysis of Bemba. Manchester: Manchester University Press.

Kashoki, M.E. (1972). 'Town Bemba: A Sketch of its Main Chracteristics.' African Social Research 13: 161-186.

Kasonde, M. A.R. (2009). Phonologie et Morphologie de la Langue Bemba. Munich: LINCOM. 
Kateule, M. (2016). A Morpho-semantic Analysis of Locatives in Town Bemba. MA Dissertation, University of Zambia.

Kula, N.C. (2016). The Conjoint-disjoint Alternation and Phonological Phrasing in Bemba, in Hyman, L.M., and Jenneke van der Wal (eds.) The Conjoint-disjoint Alternation in Bantu. Berlin/NY: Mouton de Gruyter.

Kula, N.C. (2011). Constituent Questions in Bemba. Presentation at the Bantu Psyn Workshop on WH Questions, Lyon.

Kula, N.C. (2007). 'Effects of Phonological Phrasing on Syntactic Structure.' The Linguistic Review 24: 201-231.

Kula, N.C. (2002). The Phonology of Verbal Derivation in Bemba. PhD. Dissertation University of Leiden. Utrecht: LOT Dissertation Series 65, Holland Academic Graphics.

Kula, N.C., and Bickmore, L. (2015). 'Phrasal Phonology in Copperbelt Bemba.' Phonology 32.1: 147-176.

Kula, N.C., and Cheng, L. (2007). Phonological and Syntactic Phrasing in Bemba Relatives. Journal of African Languages and Linguistics 28: 123-148.

Kula, N.C., and Marten, L. (2019). Vowel Copying in Dciriku and Mwenyi: On the Interaction Between Phonology and Semantics. Felix Banda (ed.) Theoretical and Applied Aspects of African Languages and Cultures. Festschrift in Honour of Professor Mildred Nkolola-Wakumelo. Centre for Advanced Studies of African Society (CASAS) Publication, 75-99.

Ladd, R.D. (1990). 'Metrical Representation of Pitch Register,' in Kingston and Beckman (eds.) 1990. Papers in Laboratory Phonology I: Between the Grammar and Physics of Speech, 35-57.

Ladd, R.D. (2008). Intonational Phonology. (2nd edition). Cambridge: Cambridge University Press.

Lambrecht, K. (1994). Information Structure and Sentence Form.

Leben, W.R. (1973). Suprasegmental Phonology. Doctoral Dissertation. Cambridge, MA: MIT.

Mann, M. (1977). 'An Outline of IciBemba Grammar,' in M.E. Kashoki (ed.) Language in Zambia: Grammatical Sketches. Lusaka: Institute for African Studies. Reprinted 1999, Lusaka: Bookworld Publishers.

Mwansa, J.M. (2011). The Acquisition of Object Markers in Bemba Speaking Children. $\mathrm{PhD}$. Dissertation, University of Leeds.

Mweshi, J. (2015). A Morphological Analysis of Bisa Nouns: A Dialect of the Bemba Language in Mpika District, Zambia. MA Dissertation, Kenyatta University.

Mwita, C. (2016). A Morphosyntactic Verb Inflection for Tense and Aspect in Bemba. MA Dissertation, University of Nairobi.

Myers, S. (1996). 'Boundary Tones and the Phonetic Implementation of Tone in Chichewa.' Studies in African Linguistics 25: 29-60. 
Nespor, M., and Vogel, I. (1986). Prosodic Phonology. Dordrecht: Foris Publications.

Odden, D., and Bickmore, L. (2014). 'Melodic Tone in Bantu: Overview.' Africana Linguistica 20: 3-13.

Patin, C. (2007). La Tonologie du Shingazidja, Langue Bantu (G44a) de la Grande Comore: Nature, Formalization, Interfaces. PhD Dissertation, Université Paris 3.

Philippson, G. (1998). *HH and *HL Tone Patterns in Bemba and the Bemba Tone System, in Hombert, J.M., and Hyman, L.M. (eds.) Bantu Historical Linguistics. Stanford: CSLI Publications, 395-411.

Pierrehumbert, J. (1980). The Phonology and Phonetics of English Intonation. PhD Dissertation, MIT.

Pierrehumbert, J., and Beckman, M.E. (1988). Japanese Tone Structure. Cambridge, MA: The MIT Press.

Rialland, A. (2007). 'Question Prosody: An African Perspective,' in Gussenhoven, Carlos, and Tomas Riad (eds.), Tunes and Tones, Volume 1: Typological Studies in Word and Sentence Prosody. Berlin: Mouton deGruyter, 35-62.

Rialland, A. (2009). 'The African Lax Question Prosody: Its Realisation and Geographical Distribution.' Lingua 119.6: 928-949.

Riedel, K., and Patin, C.(2011). ,Question Structure and Intonation in Fipa.' ZAS Papers in Linguistics 55: 141-160.

Sabel, J., and Zeller, J. (2006). wh-Question Formation in Nguni, in Selected Proceedings of ACAL 35: 271-283.

Selkirk, E. (1986). 'On Derived Domains in Sentence Phonology.' Phonology 3: 371-405.

Selkirk, E.O. (2011). 'The Syntax-phonology Interface,' in: Goldsmith, J. Riggle, J. and Yu, A.(eds.), The Handbook of Phonological Theory, (2nd edition). Oxford: WileyBlackwell, 435-484.

Sharman, J.C., and Meeussen, A.M. (1955). 'The Representation of Structural Tones, with Special Reference to the Tonal Behavior of the Verb in Bemba, Northern Rhodesia.' Africa: Journal of the International African Institute 25(4): 393-404.

Sharman, J.C. (1956). 'The Tabulation of Tenses in a Bantu Language' (Bemba: Northern Rhodesia). Africa 26: 29-46.

Truckenbrodt, H. (1999). 'On the Relation Between Syntactic Phrases and Phonological Phrases.' Linguistic Inquiry 30: 219-255.

Zerbian, S. (2006). 'Expression of Information Structure in the Bantu Language Northern Sotho.' ZAS Papers in Linguistics 45.

Zubizarreta, M.L. (1998). Focus, Prosody and Word Order. Cambridge MA: The MIT Press. 